NBER WORKING PAPER SERIES

\title{
MACROPRUDENTIAL POLICY: PROMISE AND CHALLENGES
}

\author{
Enrique G. Mendoza \\ Working Paper 22868 \\ http://www.nber.org/papers/w22868
}

\author{
NATIONAL BUREAU OF ECONOMIC RESEARCH \\ 1050 Massachusetts Avenue \\ Cambridge, MA 02138 \\ November 2016
}

This paper was prepared for the 20th Annual Conference of the Central Bank of Chile, Nov. 10-11, 2016. The arguments presented here draw from various projects with several co-authors I have had the privilege of collaborating with, particularly Javier Bianchi, Emine Boz, Julio Carrillo, Bora Durdu, Juan Hernandez, Victoria Nuguer, Vincenzo Quadrini, Jessica Roldan, Katherine Smith and Marco Terrones. I also benefitted from interactions with other authors in the literature on quantitative models with financial frictions, particularly Gianluca Benigno, Markus Brunnermeier, Larry Christiano, Mick Devereux, Nobu Kiyotaki, Mark Gertler, Matteo Iiacoviello, Alessandro Rebucci, Pablo Ottonello, Chris Otrok, Stephanie Schmitt-Grohe, Martin Uribe, and Eric Young. The views expressed herein are those of the author and do not necessarily reflect the views of the National Bureau of Economic Research.

NBER working papers are circulated for discussion and comment purposes. They have not been peerreviewed or been subject to the review by the NBER Board of Directors that accompanies official NBER publications.

(C) 2016 by Enrique G. Mendoza. All rights reserved. Short sections of text, not to exceed two paragraphs, may be quoted without explicit permission provided that full credit, including $\odot$ notice, is given to the source. 
Macroprudential Policy: Promise and Challenges

Enrique G. Mendoza

NBER Working Paper No. 22868

November 2016

JEL No. E44,E5,F34,F4,G01,G28

\begin{abstract}
Macroprudential policy holds the promise of becoming a powerful tool for preventing financial crises. Financial amplification in response to domestic shocks or global spillovers and pecuniary externalities caused by Fisherian collateral constraints provide a sound theoretical foundation for this policy. Quantitative studies show that models with these constraints replicate key stylized facts of financial crises, and that the optimal financial policy of an ideal constrained-efficient social planner reduces sharply the magnitude and frequency of crises. Research also shows, however, that implementing effective macroprudential policy still faces serious hurdles. This paper highlights three of them: (i) complexity, because the optimal policy responds widely and non-linearly to movements in both domestic factors and global spillovers due to regime shifts in global liquidity, news about global fundamentals, and recurrent innovation and regulatory changes in world markets, (ii) lack of credibility, because of time-inconsistency of the optimal policy under commitment, and (iii) coordination failure, because a careful balance with monetary policy is needed to avoid quantitatively large inefficiencies resulting from violations of Tinbergen's rule or strategic interaction between monetary and financial authorities.

Enrique G. Mendoza

Department of Economics

University of Pennsylvania

3718 Locust Walk

Philadelphia, PA 19104

and NBER

egme@sas.upenn.edu
\end{abstract}




\section{Introduction}

The developments that led to the 2008 global financial crisis raised a new awareness amongst central banks and financial regulators in advanced economies about the need to approach financial regulation and surveillance from a macroeconomic (i.e. systemic) and prudential (i.e. pre-emptive) perspective. Policymakers in several emerging economies learned this lesson a decade earlier, in the aftermath of the 1990s emerging markets crises, and authorities in Chile learned this lesson even earlier, with the massive banking crisis that engulfed the country in 1982. The practice of macroprudential policy, however, has marched well ahead of theoretical and quantitative research that could provide a solid foundation for it, comparable with the foundation that New Keynesian DSGE models provide for the conduct of monetary policy. The goal of watching for and containing the emergence of economy-wide credit booms and balance-sheet imbalances in financial intermediaries is widely agreed upon, based on the recurrent observation that in the years leading to financial crises credit grows "too fast," often accompanied by maturity and/or currency mismatches. But taking this notion into practice has been largely a learning-by-doing exercise, given the lack of sound quantitative models that can capture financial crises dynamics, provide market-failure arguments to justify policy intervention, and facilitate the design and evaluation of macroprudential policies.

This paper reviews a class of dynamic macro models with financial frictions that is contributing to fill these gaps, namely models with Fisherian collateral constrains (i.e. constraints limiting borrowing capacity to a fraction of the market value of assets or goods posted as collateral). Quantitative studies show that these models can replicate key stylized facts of financial crises, and that the optimal macroprudential policy of an ideal constrainedefficient financial regulator can reduce significantly the severity and frequency of financial crises. On the other hand, as this paper argues, macroprudential policy remains a difficult task. In particular, the paper highlights three major challenges:

1. Complexity: Optimal macroprudential policy rules feature significant and nonlinear variation over time and across states of nature in response to both traditional domestic factors and to global spillovers in the form of shifts in global liquidity, news about global fundamentals, and the recurrent waves of financial innovation and structural/regulatory change in world financial markets. Macroprudential regulation can be implemented with rules simpler than the optimal rules, but this requires careful design and quantitative evaluation, because otherwise it can be counterproductive and reduce welfare even relative to a status-quo without policy intervention.

2. Lack of credibility: Under commitment, macroprudential policymakers have incentives to be time-inconsistent and thus deviate from pre-announced policy rules. The argument is subtle, but at its core it has similar features as the well-known time-inconsistency arguments that undermine the credibility of optimal monetary and fiscal policies under commitment.

3. Coordination failure: Macroprudential policy needs to be carefully balanced with monetary policy. If instead of implementing separate financial policy rules, monetary policy rules are simply expanded with a financial mandate, their efficacy in terms of financial stability is weakened by the lack of sufficient policy instruments (i.e. Tinbergen's rule is violated). With separate rules, it is important that monetary and 
financial authorities coordinate so as to prevent strategic interaction from undermining the effectiveness of both policies.

This paper draws from the findings of a large and growing research program encompassing macroeconomic models of financial crises and their normative analysis. This program originated in the international macro field in the 1990s, motivated by the emerging markets crises and building on classic models of financial transmission as in Bernanke and Gertler (1989) and Kiyotaki and Moore (1997), and then became dominant in the broader macro field after the 2008 global financial crisis. The arguments developed here focus in particular on a branch of this literature that studies quantitative models with Fisherian collateral constraints (see, for example, Bianchi (2011), Bianchi and Mendoza (2010, 2016), Jeanne and Korinek (2010), Benigno et al. (2013), Mendoza and Quadrini (2010), Ottonello (2015)), and also to some extent on the large literature incorporating financial frictions into Neokeynesian DSGE models (e.g. Bernanke et al (1999), Christiano et al. (2014)).

The rest of this paper is organized as follows. Section 2 develops a general argument about the aim of macroprudential policy and the relevance of global, nonlinear methods in developing quantitative models to implement it. Section 3 provides a benchmark framework to characterize the market failure present in Fisherian models and the optimal policy response. Section 4 demonstrates the effectiveness and complexity of optimal financial policy using a variant of a framework widely used in the literature, in which income from the nontradables sector serves as collateral for debt denominated in units of tradable goods (i.e. a "liability dollarization" framework). Section 5 documents similar features in the findings reported by Bianchi and Mendoza (2016) using a model in which assets are used as collateral (i.e. a "collateral assets" framework), and also discusses time-inconsistency of the optimal policy under commitment and the quantitative implications of optimal, time-consistent policy. Section 5 examines the quantitative relevance of Tinbergen's rules and policy coordination failure resulting from the interaction of monetary and financial policies in the setup proposed by Carrillo et al. (2016). Section 6 concludes.

\section{A General Case for Nonlinear Models of Financial Crises \& Macroprudential Policy}

The appeal of macroprudential policy derives from the consensus formed around the view that credit booms, albeit infrequent, should be prevented because they end in deep, protracted crises. This view is consistent with the findings of empirical studies. For instance, the event analysis of credit booms by Mendoza and Terrones (2012) shows that credit booms occur with a frequency of only 2.8 percent in a sample of 61 industrial and emerging economies for the 19602010 period, but conditional on a credit boom, the probability of banking or currency crises is $1 / 3^{\text {rd }}{ }^{1}$ The downswings of credit booms are also typically accompanied by Sudden Stops, defined as sharp current account reversals (i.e. a sudden halt to financing from the rest of the world). After credit booms peak, the median current account reversals are roughly 2.5 and 3 percentage points of GDP in annual terms for advanced and emerging economies respectively. The recessions in the aftermath of credit booms are large and long-lasting. Three years after credit

\footnotetext{
${ }^{1}$ Mendoza and Terrones identify a country to be in a credit boom if the cyclical component of real credit per capita is in the 95 percentile of that country's distribution.
} 
booms peak, the median GDP per capita is 5 and 8 percent below trend in advanced and emerging economies respectively.

The task of macroprudential policy, as originally described by Borio (2003) or in the more recent description by Bernanke (2010), is to enrich financial regulation and financial policies with a macroeconomic, rather than microeconomic, approach to credit dynamics and systemic risk, with the goal of stopping credit booms in their early stages as a prudential measure to prevent them from turning into macro crises. While this task is clear, work in producing useful quantitative models to design and evaluate macroprudential policies has progressed slowly, largely because our understanding of how financial policies influence the transmission mechanism driving financial crises is still developing and incorporating this mechanism into quantitative dynamic macroeconomic models has proven difficult.

The NeoKeynesian DSGE models that are commonplace in central banks today have been used very successfully to evaluate monetary policy scenarios and implement inflation targeting. A comparable quantitative tool for macroprudential policy does not yet exist. Unfortunately, DSGE models have been less successful at accounting for the dynamics of financial crises, and the transition from credit boom events to financial crashes, even when the models have been extended to introduce financial mechanisms (by, for example, introducing a financial accelerator along the lines of the Bernanke-Gertler-Gilchrist, BGG, setup). Several studies (e.g. Gertler et al. (2007), Christiano et al. (2014)) show how financial transmission can be a significant factor driving macroeconomic dynamics in response to financial shocks, but modeling financial crises without relying on financial shocks in this class of models remains difficult. From a technical standpoint, this limitation is due in part to the fact that the quantitative methodology that DSGE models typically follow is based on perturbation methods, which have inherent limitations for capturing accurately the non-linear nature of the financial transmission mechanism that drives credit booms and triggers financial crises. These limitations extend into limitations for quantifying the crucial equilibrium interaction between prudential policy measures taken in good times, the optimal intertemporal plans of economic agents, and the probability and magnitude of financial crises.

The rest of this Section provides intuitive arguments about the importance of non-linear dynamics for developing quantitative frameworks to study financial crises and macroprudential policy that apply to a large class of models, in addition to the Fisherian models that this paper emphasizes. ${ }^{2}$ Consider a function relating the yield of a financial instrument to the aggregate liability position in that instrument (for example, mortgage debt of households in an advanced economy, short-term, foreign-currency denominated debt of corporations in an emerging economy, sovereign debt, etc.). It is reasonable to think that this function should be increasing and convex, like the function denoted "theoretical pricing function" in Figure 1. The convexity of this function is easier to understand by looking at the vertical intercept and asymptote. If the liability position is negligible, which means that the probability of financial distress is also negligible, the yield should be roughly the risk-free rate (i.e. the vertical intercept). The vertical asymptote exists because, since wealth in the aggregate and for a mass of agents of any size is

\footnotetext{
${ }^{2}$ Robert Merton made similar arguments about the importance of nonlinearities in modeling financial stress in terms of option pricing in his 2009 Robert A. Muh Alumni Award Lecture "Observations on the Science of Finance in the Practice of Finance" (03/05/2009).
} 
finite, there must exist a level of indebtedness such that the likelihood of non-repayment approaches $100 \%$ as that debt level is reached (i.e. the debt is so large that agents are almost certain to be unable to repay regardless of economic conditions). The vertical asymptote can therefore be thought of as a rationing threshold, at which the yield goes to infinity as the price of the liability goes to zero because repayment is a zero-probability event. In between the vertical intercept and the rationing threshold, the yield increases with the liability position and the spread between the yield on the financial liability and the riskless rate widens. The yield and the spread grow at an increasing rate (i.e. the theoretical pricing function is convex), because the increase in the probability of non-repayment in response to an increase in debt of a given amount is much larger when debt is high than when it is low.

\section{Figure 1. Theoretical Pricing Function of Financial Liabilities}

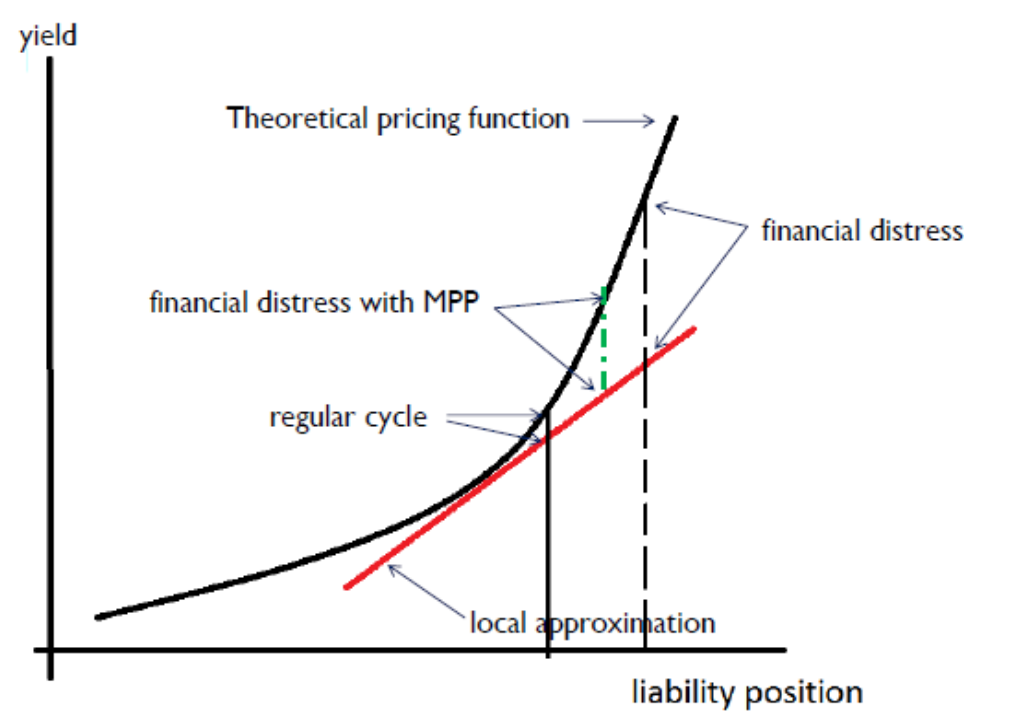

Several models used to introduce financial frictions into macroeconomic models embody convex yield functions like the one above. The list includes the Eaton and Gersovitz (1981) model of sovereign default, the financial accelerator model of Bernanke and Gertler (1989), the Kiyotaki and Moore (1997) model of collateral constraints, classic Merton models of option pricing, and several others. Note also that for the relationship to be convex, we do not require default to be explicitly modeled or that it occurs as an equilibrium outcome. In the KiyotakiMoore model, for example, there is no default.

The typical DSGE model with financial frictions focuses on a linear, or low-order, perturbation around a point in Figure 1, in an area in which financial markets are stable (i.e. spreads are small). This point is often the deterministic stationary equilibrium. As the Figure suggests, if the approximation point is in a relatively flat segment of the curve, the errors implied by the gaps between the "true" yields and those implied by the local approximation are small, and therefore of little consequence. This could be interpreted as suggesting that the perturbation method does a good job at capturing the effects of the financial transmission mechanism over the regular business cycle, in which fluctuations around cyclical averages are 
relatively small. But periods of financial distress are very different, because these are points in the steep region of the theoretical pricing function, and in that region the errors of the local approximation are large. The data could be producing yields as predicted by the theoretical pricing function, but to a modeler working with the local approximation it may look as if those outcomes are due to large, unexpected shocks (i.e. outcomes that cannot be explained within the model). ${ }^{3}$ Merton (2009) made a similar argument and concluded that: "Things are not conceptually out of control, this is not some mystery black swan we don't understand and we need to rewrite all the paradigms because all the modeling is wrong. If people are acting using a linear model, what looks like a ten-sigma event can actually be a two-sigma event..."

An important step in the modeling of financial crises is to be able to explain the transitions across the regular business cycle region and the region with financial distress, so that financial crises do not appear as large, unexpected shocks. Hence, instead of modeling crises as resulting from financial shocks, the aim is to model crises as resulting from financial amplification, defined as larger adverse effects on macroeoconomic aggregates caused by shocks of standard magnitudes when financial frictions are more active. Again in Merton's words: "Most of the models in credit, in trading desks, in macro models do quite well locally, the problem is when you stop being locally nonlinearities are really quite large,...If you want to see what happened in AIG...they wrote a whole lot of credit default swaps...the assets underlying them went down not one shock, not two shocks, not three shocks, but over and over. Each time the same size shock is going to create something even larger..."

The dynamics are non-linear locally, because for local approximations small variations in liability positions around the steep segment of the pricing function produce large changes in spreads, and also globally, since modeling the transitions between regular cycles (i.e. when financial amplification is innocuous) and financial crises (i.e. when financial amplification is large) requires capturing equilibrium dynamics across the flat and steep segments of the function. This is critically important for developing quantitative models of macroprudential policy, because the policy's stated goal is to manage financial policy tools in "good times" in the flat region of the theoretical pricing function so as to reduce the frequency of transitions into the financial instability region, and the severity of the crises that occur when those transitions do happen. This is illustrated by the shift to the liability position marked as "financial distress with MPP" in Figure 1. Hence, the quantitative framework that policymakers aiming to conduct this policy need is one in which the effects of financial policy tools on the incentives of credit-market participants in goods times are captured accurately, and the connection between these effects and the transitional dynamics between normal times and crisis times is explicitly modeled.

Of the agents' incentives that the framework needs to capture, precautionary savings is perhaps the most important, and this also requires a global approach. How does, for example, a regulatory loan-to-value ratio on mortgages with a given size and cyclical co-movement alters mortgage borrowing decisions, household leverage and the frequency and magnitude of financial

\footnotetext{
${ }^{3}$ A higher-order approximation can of course make the local results of the perturbation method more accurate at tracking the curvature of the pricing function, but to be close to the global solution it is necessary to use an approximation point that corresponds to the global equilibrium solution, otherwise a higher-order approximation does not make the solutions of local methods a good approximation to the solutions obtained using global methods (see de Groot et al. (2016)).
} 
crises? The answer hinges critically on how borrowing decisions change as the LTV requirement changes, and this response is in part determined by how the policy alters the borrowers' incentives to build buffer stock of savings (i.e. disincentives to accumulate debt), which is in turn determined by the equilibrium histories of possible future income and consumption streams that borrowers see themselves exposed to, not just one or two periods ahead, but across the entire stochastic steady state of the economy (and particularly in those low-but-positive probability financial crisis events).

Figure 1 is just a heuristic abstraction, at a high level of generality, of what an ideal model of macroprudential policy should produce. The remainder of this paper focuses on Fisherian models as one class of macro-finance models that so far has produced promising quantitative results in terms of both capturing the nonlinear dynamics of financial crises and providing a framework for studying macroprudential policy. In addition, Fisherian models provide a theoretical justification for macroprudential policy, because they embody collateral constraints that cause market failure in the form of pecuniary externalities.

\section{Pecuniary Externalities as a Rationale for Macroprudential Policy in Fisherian Models}

The defining feature of Fisherian models is an occasionally-binding collateral constraint that limits the borrowing capacity of economic agents to a fraction $\kappa$ of the market value of the goods or assets pledged as collateral. Whether this constraint binds or not is a state-contingent equilibrium outcome, which depends on the agents' optimal plans, the realizations of shocks and aggregate variables, particularly equilibrium prices. ${ }^{4}$ These models are labeled "Fisherian" because when the constraint binds they display dynamics driven by the classic debt-deflation mechanism first proposed in the seminal work of Fisher (1933). We focus on models in which this constraint is imposed directly on the optimization problems of agents, rather than modeled as an endogenous outcome of a contractual relationship between borrowers and lenders explicitly included in the models. This is common practice in a branch of the macro literature on financial frictions (e.g. Kiyotaki and Moore (1997), Aiyagari and Gertler (1999), etc.). There are, however, studies of Fisherian models in which the collateral constraint is derived from a contractual setup, typically as a result of a limited enforcement or costly-state-verification problem (e.g. Bianchi and Mendoza (2016), Mendoza and Quadrini (2010)). In addition, the pecuniary externality argument developed below applies to a wider class of financial frictions models, in which market-determined prices determine borrowing capacity. For instance, the classic Bernanke-Gertler financial accelerator model, in which borrowers pay an external financing premium as a function of their net worth that emerges endogenously as an outcome of an optimal contract, features a similar pecuniary externality, because net worth is valued at market prices and borrowers do not internalize the effect of their actions on those prices.

In generic form, the Fisherian collateral constraint is:

$$
\frac{b_{t+1}}{R_{t}} \geq-\kappa_{t} f\left(p_{t}\right)
$$

\footnotetext{
${ }^{4}$ Nothing guarantees that the constraint may actually bind along an equilibrium path. In fact, since credit constraints strengthen precautionary savings incentives, these models have a self-correcting mechanism that reduces the probability that the constraint binds, potentially even to zero.
} 
$b_{t+1}$ is an agent's position in a one-period, non-state-contingent discount bond (i.e. the agent borrows when $b_{t+1}<0$ ), with a price equal to the reciprocal of its gross return $R_{t}$, $\kappa_{t}$ is the possibly time-varying fraction of goods or assets pledgeable as collateral, $p_{t}$ represents the market-determined price of collateral, and $f($.$) is an exogenous (usually linear) function of p_{t}$.

The quantitative applications reviewed in this paper focus mostly on two specific functional forms of the collateral function $f($.$) . First, the "liability dollarization" setup for an$ economy in which debt is denominated in units of tradables and collateral is posted in terms of the income from tradable and nontradable sectors, $y_{t}^{T}$ and $y_{t}^{N}$ respectively. This setup originated in Mendoza (2002), and has been used widely in models of macroprudential policy (e.g. Bianchi (2011), Benigno et al. (2013), Korinek (2011), Bianchi et al. (2016)). In this case, $b_{t+1}$ is in units of tradables and $f()=.y_{t}^{T}+p_{t}^{N} y_{t}^{N}$, where $p_{t}^{N}$ is the relative price of nontradable goods to tradable goods. Hence, debt cannot exceed a fraction $\kappa_{t}$ of total income in units of tradables, and the price determining the value of collateral is $p_{t}^{N}$. Second, the "collateral assets" setup in which an asset $k_{t+1}$ (e.g. land, houses, a firm's physical capital) serves as collateral and $f()=$. $q_{t} k_{t+1}$, where $q_{t}$ is the market price of the asset in units of consumption goods. Hence, in this case $\kappa_{t}$ represents an upper bound on the loan-to-value ratio These models are similar in structure to Kiyotaki and Moore (1997) and Aiyagari and Gertler (1999) and have been used in quantitative studies of financial crises such as those by Mendoza and Smith (2006) and Mendoza (2010), and in studies of macroprudential policy by Bianchi and Mendoza (2010,2016) and Jeanne and Korinek (2010).

There are several variations of the above Fisherian collateral constraint in the literature. One case we will examine later extends debt to include both intertemporal debt and withinperiod debt in the form of working capital financing used by producers to pay for inputs. There are also formulations that allow for endogenous production, capital accumulation, asset trading and financial intermediation. In liability dollarization models with production, the Fisherian deflation of $p_{t}^{N}$ affects aggregate supply by reducing demand for inputs in the nontradables sector (e.g. Durdu et al. (2009)). If labor income is included in the pledgeable collateral, the constraint increases the effective returns to labor supply, since additional labor income enhances borrowing capacity (e.g. Mendoza (2002), Benigno et al. (2013)). In models with capital accumulation, the Fisherian deflation hits Tobin's Q and thus has both supply and demand effects, because it causes a collapse in investment and thus in future physical capital (e.g. Mendoza (2010)). Models in which assets are traded internationally have a similar feature that triggers asset fire sales and price collapses when the constraint binds, but since the assets are sold to foreign investors, the response of the equilibrium price depends on additional financial frictions, such as trading costs and short-selling constraints (see Mendoza and Smith (2006,2014)). Mendoza and Quadrini (2010) study a model in which banks subject to a mark-tomarket capital requirement intermediate funds between heterogeneous households and a representative firm with a collateral constraint.

In the remainder of this Section, the goal is to develop the market-failure argument that justifies macroprudential policy when collateral constraint (1) is present. The essence of the argument is that the fact that collateral is valued at market prices in the right-hand-side of (1) creates a pecuniary externality. Pecuniary externalities are generally benign, because they do not distort allocations, but in models of this class they do. Of particular interest for macroprudential policy (since it is a pre-emptive policy) is a state of nature in which the 
collateral constraint does not bind at date $\mathrm{t}$ but can bind with some probability at $\mathrm{t}+1$. In this case, agents make borrowing decisions equating the marginal cost and benefit of the additional unit of debt they take on at date $t$, but in the marginal cost they do not internalize the response of collateral values at $t+1$ if the credit constraint becomes binding. As a result, private and social marginal costs of borrowing differ.

The above argument can be articulated more formally as follows. In general equilibrium, the market value of collateral corresponds to marginal rates of substitution in consumption and/or marginal rates of technical substitution in production. Because this is a general equilibrium outcome, individual borrowers do not internalize the effects of their own borrowing decisions on the aggregate variables that pin down the value of collateral via these equilibrium conditions, but a social planner does, because the planner internalizes that prices depend on allocations. Thus, from the planner's perspective, prices in the collateral function are actually a function of aggregate allocations. In the standard liability dollarization setup with endowment incomes, the relevant marginal rate of substitution for the value of collateral is that between consumption of tradables and nontradables, and since nontradables are usually an endowment, we can re-write the collateral function as $f\left(p_{t}\left(C_{t}^{T}\right)\right)$, where $C_{t}^{T}$ is the aggregate value of consumption of tradables. In the collateral assets setup, the relevant marginal rate of substitution is the intertemporal one (or the stochastic discount factor), so the collateral function can be expressed as $f\left(p_{t}\left(C_{t}, C_{t+1}\right)\right)$. Notice a subtle difference in these two collateral functions: In the liability dollarization model, the function depends only on date-t aggregate variables, whereas in the collateral assets model it depends on date- $t$ and date $t+1$ variables. This difference has crucial implications for time-consistency and credibility of optimal macroprudential policy that we will highlight later in the paper.

In general, dynamic macroeconomic models with Fisherian collateral constraints have in common that in a decentralized equilibrium without policy intervention the households' Euler equation for bond holdings takes the following form:

$$
u^{\prime}(t)=\beta R_{t} E\left[u^{\prime}(t+1)\right]+\mu_{t}
$$

The non-negative Lagrange multiplier on the collateral constraint $\left(\mu_{t}\right)$ enters as a wedge that represents the fact that the effective cost of borrowing exceeds $R_{t}$ when the constraint binds.

Optimal policy problems for Fisherian models are typically written following the "primal approach," as constrained-efficient problems in which a regulator chooses bond holdings directly internalizing the dependency of the value of collateral on consumption and borrowing choices. Optimality conditions for these problems take different forms depending on the particular structure of models, and especially on whether prices in the collateral function depend on contemporaneous and/or future aggregate variables. Differences along these lines yield different implications as to whether the social planner problem calls for policy intervention when the collateral constraint binds and/or before it becomes binding. To characterize the macroprudential pecuniary externality, however, we abstract from the former by assuming a state of nature in which the collateral constraint does not bind at date $t$. In this case, the planner's Euler equation for bonds typically takes this form: 


$$
u^{\prime}(t)=\beta R_{t} E\left[u^{\prime}(t+1)+\mu_{t+1}^{*} \kappa_{t+1} f^{\prime}(t+1) \frac{\partial p_{t+1}}{\partial \tilde{C}_{t+1}} \frac{\partial \tilde{C}_{t+1}}{\partial b_{t+1}}\right]
$$

Where $\mu_{t}^{*}$ is the multiplier of the collateral constraint in the planner's problem and $\tilde{C}_{t+1}$ is the relevant aggregate variable for determining prices in the collateral function. The second term inside the brackets in the right-hand-side of this expression reflects the planner's assessment of the effect of the date-t's borrowing choice $b_{t+1}$ on $\tilde{C}_{t+1}$, which in turn determines the value of collateral and borrowing capacity at $t+1$. This assessment is only relevant in states of nature in which the constraint is expected to bind (i.e. if $\mu_{t+1}^{*}>0$ ). This is an externality because it captures price effects that are the aggregate result of individual choices, and as such are not internalized by private agents. Clearly, since we are assuming that the constraint does not bind at $\mathrm{t}$, it follows from condition (2) that the private marginal cost of borrowing is only $\beta R_{t} E\left[u^{\prime}(t+1)\right]$, and hence as long as $f^{\prime}(t+1)\left(\partial p_{t+1} / \partial \tilde{C}_{t+1}\right)\left(\partial \tilde{C}_{t+1} / \partial b_{t+1}\right)>0$ the social marginal cost of borrowing is higher. In other words, agents in the economy without policy intervention have the incentive to "overborrow," because they undervalue the marginal cost of borrowing.

The property that $f^{\prime}(t+1)\left(\partial p_{t+1} / \partial \tilde{C}_{t+1}\right)\left(\partial \tilde{C}_{t+1} / \partial b_{t+1}\right)>0$ is critical for the above argument. The positive sign of $f^{\prime}\left(p_{t+1}\right)$ can be safely imposed by assumption, since the form of $f($.$) is chosen$ exogenously and is generally linear in the value of collateral. In the liability dollarization setup $f^{\prime}\left(p_{t+1}\right)=y_{t}^{N}>0$, and in the asset pricing setup $f^{\prime}\left(p_{t+1}\right)=K_{t+1}>0$, where $K_{t+1}$ is the aggregate supply of assets in the economy, and in both of these setups $y_{t}^{N}$ and $K_{t+1}$ are often modeled as exogenous endowments. Also, $\partial \tilde{C}_{t+1} / \partial b_{t+1}>0$ follows from standard budget constraints, and in fact in both liability dollarization and collateral asset models $\partial \tilde{C}_{t+1} / \partial b_{t+1}=1 .^{5}$ On the other hand, since prices are general equilibrium outcomes, the sign of $\partial p_{t+1} / \partial \tilde{C}_{t+1}$ is also an equilibrium outcome, and thus $\partial p_{t+1} / \partial \tilde{C}_{t+1}>0$ cannot be assumed, it needs to be established as a property of the equilibrium. As it turns out, in relatively simple variants of both the liability dollarization and collateral assets setups, this property of the equilibrium pricing function holds because of the concavity of utility functions. The equilibrium pricing function derivatives in the liability dollarization and collateral assets models respectively are: ${ }^{6}$

$$
\begin{aligned}
& \frac{\partial p_{t+1}^{N}}{\partial C_{t+1}^{T}}=\frac{-p_{t+1}^{N} u_{c^{T} c^{T}}(t+1)}{u_{c^{T}}(t+1)}>0 \\
& \frac{\partial q_{t+1}}{\partial C_{t+1}}=\frac{-q_{t+1} u_{c c}(t+1)}{u_{c}(t+1)}>0
\end{aligned}
$$

The optimal allocations of the social planner produced by the "primal approach" are generally decentralized in the literature using a state-contingent tax on debt (sometimes referred to as a Pigouvian tax) with the revenues rebated as a lump-sum transfer. The optimal

\footnotetext{
${ }^{5}$ For example, the standard resource constraint for consumption of tradables in the liability dollarization setup is $c_{t}^{T}=y_{t}^{T}-q_{t} b_{t+1}+b_{t}$, so that $\partial C_{t}^{T} / \partial b_{t}=1$

${ }^{6}$ In these expressions, $p_{t+1}$ is replaced with the relevant price from each model, and we simplify to obtain prices in the numerators using the optimality conditions for sectoral allocation of consumption in the liability dollarization setup and the Euler equation for assets in the collateral assets setup.
} 
macroprudential tax on debt $\tau_{t}$ is defined as the one that makes private agents in the decentralized equilibrium with the tax face the same marginal cost of borrowing as the social planner in states of nature in which $\mu_{t}^{*}=0$ and $\mathrm{E}_{\mathrm{t}}\left[\mu_{t+1}^{*}>0\right]$. Hence, the optimal $\tau_{t}$ levied on the decentralized economy with taxes is simply the one that matches the value of the pecuniary externality in the planner's optimality condition (3) (i.e. a tax schedule such that the righthand-side of (3) and that of the corresponding Euler equation in the decentralized economy with taxes yield identical values). The optimal macroprudential debt tax is:

$$
\tau_{t}=\frac{E_{t}\left[\mu_{t+1}^{*} \kappa_{t+1} f^{\prime}(t+1) \frac{\partial p_{t+1}}{\partial \tilde{C}_{t+1}} \frac{\partial \tilde{C}_{t+1}}{\partial t_{t+1}}\right]}{E_{t}\left[u^{\prime}(t+1)\right]}
$$

This tax is strictly positive, because it inherits the sign of the pecuniary externality, and thus once it is established that $\partial p_{t+1} / \partial \tilde{C}_{t+1}>0$ it follows that the $\tau$ is strictly positive when $\mathrm{E}_{\mathrm{t}}\left[\mu_{t+1}^{*}>0\right]$.

Taxes are a natural way of decentralizing the optimal policy because we are dealing with an externality. In practice, however, financial regulators rarely operate with standard tax instruments, and in the conduct of macroprudential policy what we tend to see more generally is the use of instruments such as regulatory LTV and LTI ratios, rules for banks' liquidity coverage or capital buffers with a countercyclical element. It is straightforward to see that the optimal macroprudential policy can be decentralized in terms of regulatory LTV or LTI ratios instead of taxes. In this case, the aim would be to adjust the value of the "unregulated" collateral coefficient $\kappa_{t}$ with a time- and state-contingent adjustment that does not let private agents borrow above the amount indicated by the social planner's decision rules. Bianchi (2011) shows how the optimal policy can also be decentralized with capital requirements.

Four important caveats to the case for macroprudential policy presented here should be noted: First, alternative formulations of the collateral constraint can yield "underborrowing" and debt subsidies (e.g. Benigno et al. (2013)). Second, depending on model structure and parameter values, there can be multiple competitive equilibria if there are more than one value of $b_{t+1}$ that satisfy the collateral constraint with $\mu_{t}>0$ (see Schmitt-Grohe and Uribe (2016) and Mendoza (2005)). Third, also depending on model structure, the social planner may have incentives to intervene not just with macroprudential policy (i.e. policy that applies when $\mu_{t}^{*}=0$ and $\mathrm{E}_{\mathrm{t}}\left[\mu_{t+1}^{*}>0\right]$ ) but also with ex-post policy (i.e. policy that applies when $\mu_{t}^{*}>0$ ). For instance, in a liability dollarization model with production, the planner would like to reallocate inputs from nontradables to tradables production when $\mu_{t}^{*}>0$, because this props up the value of collateral and makes the constraint less binding (see Hernandez and Mendoza (2016)). Fourth, if collateral values at date $t$ are determined jointly by date- $t$ and date- $t+1$ allocations, the optimal plans of the social planner can be time-inconsistent under commitment (see Bianchi and Mendoza (2016)). This fourth issue is particularly relevant for policy evaluation, because timeinconsistency undermines the credibility of the policy, and will be discussed in Section 5 .

\section{Complexity of the Optimal Policy in a Liability Dollarization Setup}

This Section uses a specific quantitative example based on the liability dollarization setup to illustrate two points. First, Fisherian models produce financial crises with realistic 
features, because they embody a strong financial amplification mechanism. Second, these models yield very favorable results about the effectiveness of optimal macroprudential policy, because of large pecuniary externalities. The specific formulation of the liability dollarization model is based on Hernandez and Mendoza (2016), which in turn follows from Bianchi et al. (2016).

\section{(a) A Liability Dollarization Model with Production 8 Unconventional Shocks}

Consider a small open economy in which agents produce and consume tradable and nontradable goods. A representative household chooses sequences of $b_{t+1}, c^{T}{ }_{t}$, and $c^{N}{ }_{t}$ so as to solve the following optimization problem:

subject to:

$$
\max E_{0}\left[\sum_{t=0}^{\infty} \beta \frac{c_{t}^{1-\gamma}}{1-\gamma}\right], \quad c_{t}=\left[\omega\left(c_{t}^{T}\right)^{-\eta}+(1-\omega)\left(c_{t}^{N}\right)^{-\eta}\right]^{-\frac{1}{\eta}}
$$

$$
\begin{gathered}
q_{t} b_{t+1}+c_{t}^{T}+p_{t}^{N} c_{t}^{N}+A^{T}+p_{t}^{N} A^{N}=b_{t}+\pi_{t}^{T}+\pi_{t}^{N} \\
q_{t} b_{t+1} \geq-\kappa\left(\pi_{t}^{T}+\pi_{t}^{N}\right)
\end{gathered}
$$

Preferences are standard, with a CRRA utility function and a CES consumption aggregator of consumption of tradables and nontradables $(1 /(1+\eta)$ is the elasticity of substitution across the two). In the right-hand-side of the budget and borrowing constraints, $\pi^{T}$ and $\pi^{N}$ are profits from production in the tradables and nontradables industries. $A^{T}$ and $A^{N}$ are autonomous spending constants that correspond to investment and government purchases so as to allow the model to be calibrated to observed consumption-output ratios.

Representative firms produce tradables and nontradables using intermediate goods, $m^{T}{ }_{t}$ and $m^{N}$ in each industry respectively, as the only variable input in standard Neoclassical production functions. These intermediate goods are tradable goods with a constant worlddetermined relative price of $p^{m}$ in units of the tradable consumer goods. Firms choose their demand for inputs so as to maximize profits:

$$
\begin{gathered}
\max _{m_{t}^{T}} \pi_{t}^{T}=z_{t}^{T}\left(m_{t}^{T}\right)^{\alpha^{T}}-p^{m} m_{t}^{T} \\
\max _{m_{t}^{N}} \pi_{t}^{N}=p_{t}^{N} z_{t}^{N}\left(m_{t}^{N}\right)^{\alpha^{N}}-p^{m} m_{t}^{N}
\end{gathered}
$$

Notice that, because profit maximization will require equating the value of the marginal product of inputs in each sector with $p^{m}$, total profits at equilibrium (which are the collateral for debt) are given by $\pi_{t}^{T}+\pi_{t}^{N}=\left(1-\alpha^{T}\right) z_{t}^{T}\left(m_{t}^{T}\right)^{\alpha^{T}}+\left(1-\alpha^{N}\right) p_{t}^{N} z_{t}^{N}\left(m_{t}^{N}\right)^{\alpha^{N}}$. Hence, at equilibrium, the borrowing constraint of this economy depends on $p^{N}$ even though it does not enter explicitly in the collateral constraint that households "see."

As in Bianchi et al. (2016), the model includes three types of shocks. First, standard TFP shocks hitting both producers, $z_{t}^{i}$ for $i=N, T$. Second, noisy news about future fundamentals in the form of a signal $s_{t}$ received at date $\mathrm{t}$ about the date-t+1 TFP in the tradables sector $z^{T}{ }_{t+1}$. Third, shifts in global liquidity, modeled as regime-switches in the world interest rate, which is 
the inverse of $q_{t}$. The rationale for introducing these two "unconventional" shocks is to capture effects from conditions in global markets (e.g. commodity price news, Shin's (2013) "phases of global liquidity") by which shocks and policy decisions from the rest of the world spillover into domestic financial stability conditions and macroeconomic fluctuations.

Noisy news are modeled as in Durdu et al. (2013). The signals have the same number $N$ of realizations as the TFP shocks and they satisfy the following condition:

$$
p\left(s_{t}=i \mid z_{t+1}^{T}=l\right)=\left\{\begin{array}{c}
\theta \quad \text { if } i=l \\
\frac{1-\theta}{N-1} \quad \text { if } i \neq l
\end{array}\right.
$$

The parameter $\theta$ determines the precision of the signals. News are perfectly precise if $\theta=1$, because in that case the particular TFP signal received at $t$ is exactly the realization observed at $\mathrm{t}+1$. At the other extreme, news are perfectly uninformative if $\theta=1 / N$, because a particular TFP signal received at $t$ has an equal probability of being associated with all possible TFP realizations at $t+1$. Agents use these signals to improve their (Bayesian) rational expectations of the evolution of TFP in the tradables sector (see Bianchi et al. (2016) for details).

Global liquidity shifts are modeled as a standard Hamilton-style Markov switching process across two regimes, one with a low world real interest rate (high bond price, $q^{H}$ ) and one with a high interest rate (low bond price, $q^{L}$ ). The one-step transitional probabilities of continuation of each regime are $\mathrm{F}_{\mathrm{HH}}$ and $\mathrm{F}_{\mathrm{LL}}$, and the mean durations of high and low liquidity regimes are therefore $1 /\left(1-\mathrm{F}_{\mathrm{LL}}\right)$ and $1 /\left(1-\mathrm{F}_{\mathrm{HH}}\right)$.

Noisy news and liquidity shifts are important to consider in models of financial transmission. For example, good news received in date $t$ about commodity prices at date $t+1$ is akin to a form of optimism that induces agents to borrow more and to expect higher future borrowing capacity. If at $\mathrm{t}+1$ the realized prices are actually low, the economy can become financially fragile as it will be carrying higher debt and leverage than in the absence of the noisy news. Similarly, if the world is in a regime of high liquidity (e.g. following commitments to quantitative easing by central banks in advanced economies), agents also have the incentive to take on more debt, so when a shift to low liquidity occurs it can trigger financial instability both directly because of the sudden large reversal in liquidity and indirectly because agents will be carrying higher debt and leverage that in the case in which the interest rate is constant or modeled as a smooth time-series process.

When the collateral constraint becomes binding in the decentralized competitive equilibrium of this economy, tradables consumption falls because access to credit is limited. This in turn causes the market-clearing price of nontradables to drop. This reduces the value of the marginal product of inputs in the $\mathrm{N}$ sector, causing a drop in demand for inputs and in production from this sector, which also implies that profits from this sector fall. The Fisherian deflation occurs because as both the price and profits from the $\mathrm{N}$ sector fall, the collateral constraint hitting the household becomes more binding, causing a feedback loop by which tradables consumption falls more, the price, production and profits from nontradables fall more, and the collateral constraint binds more. ${ }^{7}$

\footnotetext{
${ }^{7}$ Note that since production of nontradables falls, for the relative price to fall it must be the case that the effect of the collateral constraint reducing tradables consumption is larger than the decline in
} 
The optimal financial policy in this economy is characterized by the allocations that solve the following recursive constrained-efficient planner's problem (using $\varepsilon$ to represent a set of realizations of each shock, $\left.\varepsilon=\left(z^{T}, z^{N}, s, q\right)\right)$ :

subject to:

$$
V(b, \varepsilon)=\max _{b^{\prime}, c^{T}, c^{N}, m^{T}, m^{N}}\left[\frac{\left(\left[\omega\left(c^{T}\right)^{-\eta}+(1-\omega)\left(c^{N}\right)^{-\eta}\right]^{-\frac{1}{\eta}}\right)^{1-\gamma}}{1-\gamma}+\beta E V\left(b^{\prime}, \varepsilon^{\prime}\right)\right]
$$

Constraints (14)-(15) are the resource constraints in the $\mathrm{T}$ and $\mathrm{N}$ sectors respectively. Constraint (16) is the collateral constraint as faced by the planner, which internalizes that profits at equilibrium correspond to the share $\left(1-\alpha^{i}\right)$, for $\mathrm{i}=\mathrm{N}, \mathrm{T}$. of each sector's output in units of tradables. Constraint $(17)$ is an implementability constraint that corresponds to the optimality condition for sectoral consumption allocations in the competitive equilibrium. Intuitively, the planner, when recognizing the connection between the price of nontradables and borrowing capacity, takes into account that its optimal plans must be consistent with prices that can be supported as a market outcome in which markets remain private and competitive.

Following the arguments from the previous Section, we can conclude that this economy features the same pecuniary externality according to which the planner internalizes the effect of today's borrowing choice on tomorrow's value of collateral when the collateral constraint binds. Deriving the optimality conditions of the decentralized equilibrium and the planner's problem, and comparing them following the arguments of Section 2, we can obtain the following expression for the planner's Euler equation for bonds:

$$
q_{t} u_{c^{T}}(t)=\beta E_{t}\left[u_{c^{T}}(t+1)+\mu_{t+1}^{*} \kappa(1+\eta) \frac{p_{t}^{N}\left(1-\alpha^{N}\right) z_{t}^{N}\left(m_{t}^{N}\right)^{\alpha^{N}}}{c_{t}^{T}}\right]
$$

The second term in the brackets in the right-hand-side of this expression corresponds to this model's pecuniary externality when the constraint does not bind today but can bind tomorrow

nontradables consumption implied by the fall in output of nontradables. In addition, there is the possibility of equilibrium multiplicity if a condition that requires $\kappa$ to be relatively high compared to the product of $(1+\eta)$ and the ratio of profits from nontradables to consumption of tradables holds. 
in some states of nature. Again following the arguments in Section 2, this externality yields the following optimal macroprudential debt tax:

$$
\tau_{t}^{b}=\frac{E_{t}\left[\mu_{t+1}^{*} \kappa(1+\eta) \frac{p_{t}^{N}\left(1-\alpha^{N}\right) z_{t}^{N}\left(m_{t}^{N}\right)^{\alpha^{N}}}{c_{t}^{T}}\right]}{E_{t}\left[u_{c^{T}}(t+1)\right]}
$$

In this economy, however, there is not only macroprudential (i.e. ex ante) policy, but also financial policy in a broader sense, because the planner also has the incentive to intervene when the collateral constraint is binding at date t. In particular, when the constraint binds, the planner finds it optimal to introduce wedges in the factor allocation conditions as follows:

$$
\begin{gathered}
\alpha^{N} p_{t}^{N} z_{t}^{N}\left(m_{t}^{N}\right)^{\alpha^{N}-1}=p^{m}\left[\frac{\lambda_{t}}{\lambda_{t}+\mu_{t}^{*} \kappa\left(1-\alpha^{N}\right)\left(1-\left(\frac{p_{t}^{N} c_{t}^{N}+c_{t}^{T}}{c_{t}^{T}}\right)\left(1+\frac{A^{T}}{c_{t}^{N}}\right)\right)}\right] \\
\alpha^{T} z_{t}^{T}\left(m_{t}^{T}\right)^{\alpha^{T}-1}=p^{m}\left[\frac{\lambda_{t}}{\lambda_{t}+\mu_{t}^{*} \kappa\left(1-\alpha^{T}\right)}\right]
\end{gathered}
$$

In these expressions, $\lambda$ denotes the Lagrange multiplier on the resource constraint for tradables. The wedge in the factor allocation condition of the $\mathrm{N}$ sector (the term in square brackets in condition (20)) is smaller than 1 , because the second term in the denominator is negative. The wedge in the factor allocation of the $\mathrm{T}$ sector (the term in square brackets in condition (21)) is greater than 1, because the second term in the denominator is positive. Hence, the social marginal cost of allocating inputs to produce $\mathrm{N}(\mathrm{T})$ goods is higher (lower) than the private marginal cost $\left(p^{m}\right)$, because the planner realizes that by reallocating inputs and production in this way it can prop up the value of collateral, which is socially valuable when the collateral constraint binds. These socially optimal factor allocations can be decentralized by imposing the following time- and state-contingent taxes $\tau^{N}{ }_{t}$ (subsidies $s^{T}{ }_{t}$ ) on the $\mathrm{N}(\mathrm{T})$ sector:

$$
\begin{gathered}
\tau_{t}^{N}=\left[\frac{\lambda_{t}}{\lambda_{t}+\mu_{t}^{*} \kappa\left(1-\alpha^{N}\right)\left(1-\left(\frac{p_{t}^{N} c_{t}^{N}+c_{t}^{T}}{c_{t}^{T}}\right)\left(1+\frac{A^{T}}{c_{t}^{N}}\right)\right)}\right]-1 \\
s_{t}^{T}=1-\left[\frac{\lambda_{t}}{\lambda_{t}+\mu_{t}^{*} \kappa\left(1-\alpha^{T}\right)}\right]
\end{gathered}
$$

The government budget constraint in this setup is $\operatorname{Tr}_{t}=-\frac{\tau q_{t} b_{t+1}}{1+\tau}+\tau_{t}^{N} m_{t}^{N}-s_{t}^{T} m_{t}^{T}$, where $T r_{\mathrm{t}}$ is a lump-sum tax (if negative) or transfer (if positive) to individuals. Notice that if $\operatorname{Tr}_{t}<0$, the assumption of lump-sum taxation can be troublesome because it gives the government a distortion-free mechanism to reallocate resources. In such a case, it would be more sensible to 
require the government to raise the revenue needed to pay for the optimal financial policies using distortionary taxes, and take this additional distortion into consideration when designing the optimal policy. This is only an issue here in states when the collateral constraint binds and if the revenue raised by the macroprudential debt tax and the nontradables producers tax is less than the cost of the subsidy to tradables producers.

\section{(b) Quantitative Findings}

Hernandez and Mendoza (2016) calibrate the model using data for Colombia (previous applications of the liability dollarization model have used data for Mexico and Argentina). The parameter values are listed in Table 1 , and the details of the calibration are available in their paper. They solve the model using nonlinear global methods (a time-iteration algorithm with the occasionally binding constraint, news shocks and regime-switching in the interest rate adapted from the work of Bianchi et al. (2016)). We are interested in two features of the results. First, the Fisherian amplification mechanism produces financial crises with realistic features. Second, the optimal financial policy (both macroprudential and ex-post intervention) is very effective at reducing the frequency and magnitude of crises and increasing social welfare.

Table 1. Calibration of Liability Dollarization Model

\begin{tabular}{lccc}
\hline \hline Parameter & & Value & Target \\
\hline Risk Aversion & $\gamma$ & 2.000 & Standard value \\
Elasticity of Subs. & $\eta$ & 0.205 & Bianchi et al. (16) \\
Consumption Aggregator & $\omega$ & 0.415 & Share of tradable output \\
News Precision & $\theta$ & $2 / 3$ & Bianchi et al. (16) \\
T Input \% in T Sector & $\alpha_{T}$ & 0.420 & Avg. \% of T input/T Gross out. \\
T Input \% in NT Sector & $\alpha_{N}$ & 0.158 & Avg. \% of T input/NT Gross out. \\
Autocorr. T prod. & $\rho_{z}^{T}$ & 0.845 & Output Autocorrelation \\
SD T prod. & $\sigma_{z}^{T}$ & 0.016 & Output Volatility \\
Low Liq. Real Int. Rate & $R^{h}$ & 1.013 & Bianchi et al. (16) \\
High Liq. Real Int. Rate & $R^{l}$ & 0.992 & Bianchi et al. (16) \\
Low Liq. Cont. Prob. & $F_{h h}$ & 0.983 & Bianchi et al. (16) \\
High Liq. Cont. Prob. & $F_{l l}$ & 0.900 & Bianchi et al. (16) \\
\hline Discount Factor & $\beta$ & 0.989 & Avg. Colombian NFA/GDP \\
\% Assets Pledgeable & $\kappa$ & 0.850 & Crisis probability \\
\hline \hline
\end{tabular}

Table 2 reports key moments that summarize financial-crises features of both the decentralized equilibrium without policy intervention (DE) and the social planner's equilibrium with the optimal financial policy (SP), together with additional results for simpler policy rules that will be discussed later. Consider first the features of financial crises in the DE. Crises occur with 2.8 percent probability, as an implication of the calibration target for the value of $\kappa$. On average, when a financial crisis hits (defining financial crises as in empirical studies, in terms of changes exceeding two standard deviations in the credit flow, which in this case is also the 
current account), the impact effects are: A 6 percent decline in consumption, an 8 percent decline in the real exchange rate, and a reversal of the current account of nearly 800 basis points. Thus, financial amplification produces crises with realistic features in terms of the responses of consumption and the current account, compared with actual features of Sudden Stops in emerging economies (see Mendoza (2010)).

Global spillovers via regime-switches in the interest rate and/or noisy news about the future productivity of the tradables sector (or future terms of trade), play an important roles in these results. In particular, as previously documented in the results of Bianchi et al. (2016), in all financial crises events in the model the realization of $z_{t}$ is low, but the signal about this realization was average or good in about $1 / 3^{\text {rd }}$ of the crises. Hence, positive news about global fundamentals that turn out to be "false optimism" ex-post is a source of financial instability

Table 2. Comparison of Equilibria with and without Financial Policies

\begin{tabular}{ccccc}
\hline \hline & $(1)$ & $(2)$ & $(3)$ & $(4)$ \\
Long-run Moments & DE & SP & CT @ Opt. & CT @ SPavg \\
\hline $\mathbb{E}[B / Y]$ & $77.35 \%$ & $74.95 \%$ & $70.86 \%$ & $75.7 \%$ \\
$\sigma(C A / Y)$ & 0.023 & 0.009 & 0.019 & 0.022 \\
Welfare Gain & n.a. & $1.38 \%$ & $0.9 \%$ & $0.4 \%$ \\
Prob. Of Crisis & $2.80 \%$ & $0.00 \%$ & $1.39 \%$ & $2.48 \%$ \\
$\operatorname{Pr}\left(\mu_{t}>0\right)$ & $15.57 \%$ & $4.95 \%$ & $11.92 \%$ & $14.60 \%$ \\
\hline \multicolumn{5}{c}{} \\
\hline Financial Crisis Moments & $-6.03 \%$ & $-1.57 \%$ & $-5.24 \%$ & $5.42 \%$ \\
\hline$\Delta C$ & $-7.99 \%$ & $-1.08 \%$ & $-7.93 \%$ & $-7.35 \%$ \\
$\Delta R E R$ & $7.70 \%$ & $-0.31 \%$ & $3.42 \%$ & $6.43 \%$ \\
$\Delta C A / Y$ & n.a. & $0.1 \%$ & $0.1 \%$ & $0.3 \%$ \\
$\mathbb{E}[\tau]$ pre-crisis & n.a. & $0.1 \%$ & $0.0 \%$ & $0.0 \%$ \\
$\mathbb{E}\left[s^{T}\right]$ pre-crisis & n.a. & $0.8 \%$ & $0.0 \%$ & $0.0 \%$ \\
$\mathbb{E}\left[\tau^{N}\right]$ pre-crisis &
\end{tabular}

Comparing the DE v. the SP in Table 2 (columns (1) and (2)) shows that the optimal policy is very effective in this setup. Crises are completely removed (i.e. changes in the current account of magnitudes comparable to those in the DE become zero probability event). When faced with shocks of the same magnitudes as the DE economy in the crisis states, the responses of consumption and the real exchange rate are much smaller, and the current account is nearly unchanged. Social welfare, measured as a compensating variation in consumption that renders agents indifferent between the DE and DP in terms of expected lifetime utility, is 1.4 percent higher in the SP economy, which is a significant welfare gain.

The average of the macroprudential debt tax and the subsidy on tradables production is about 0.1 percent (in the year before financial crises hit in the DE economy to make them comparable), while the tax on nontradables production is 0.8 percent. Debt taxes are used more frequently, with a long-run probability of almost 12 percent, while the long-run probability of using the production tax and subsidy, which are states in which $\mu_{t}>0$, is roughly 5 percent. 
Hernandez and Mendoza (2016) and Bianchi et al. (2016) document in detail the complexity of the optimal policies by studying the variation of the optimal taxes both in the time-series dimension and in the schedules of taxes across values of debt and realizations of the various shocks. Figure 2 illustrates some of this complexity by showing the optimal policy schedules as functions of the value of $b$ for regimes with high (blue, continuous curves) and low (green, dashed curves) world interest rates in pairs of panels for each tax that correspond to bad news and good news in $s$, both coinciding with bad realizations of $z$.

Figure 2. Complexity of the Optimal Policy

(a) Debt tax
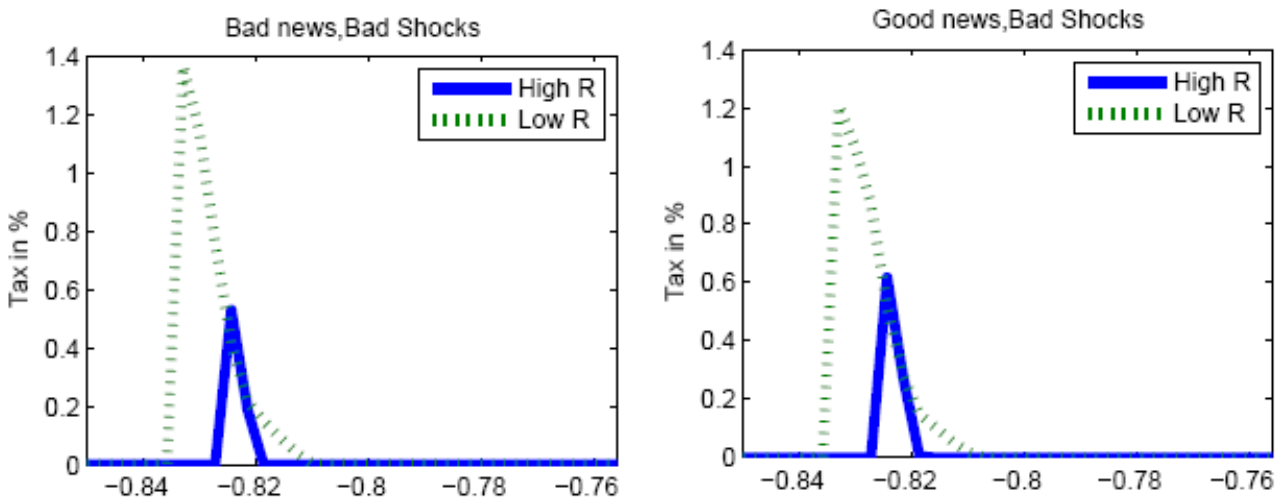

(b) Subsidy on tradables production
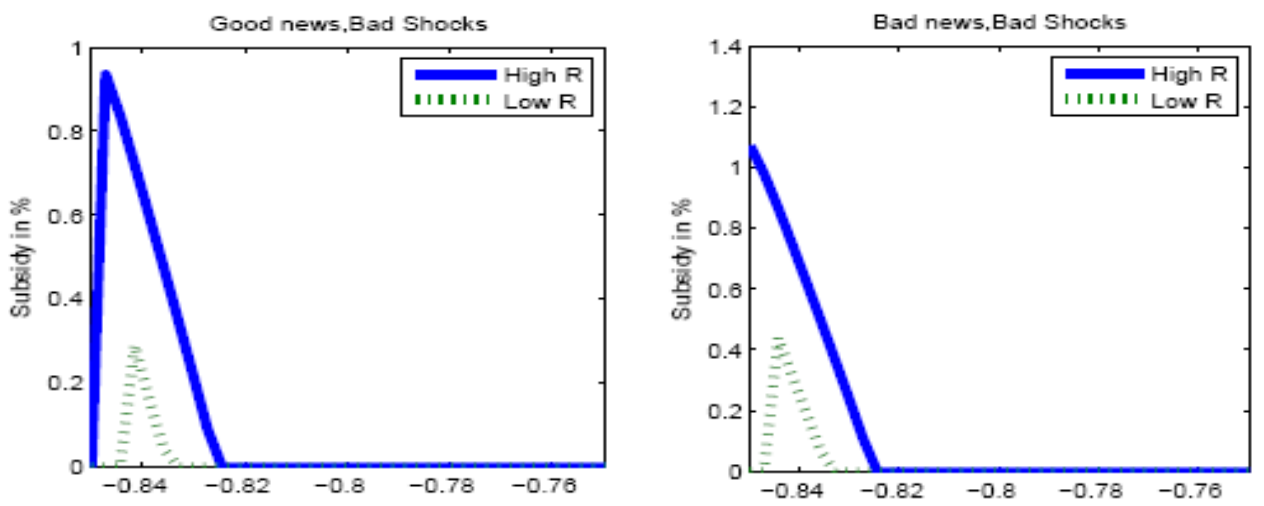

(c) Tax on nontradables production
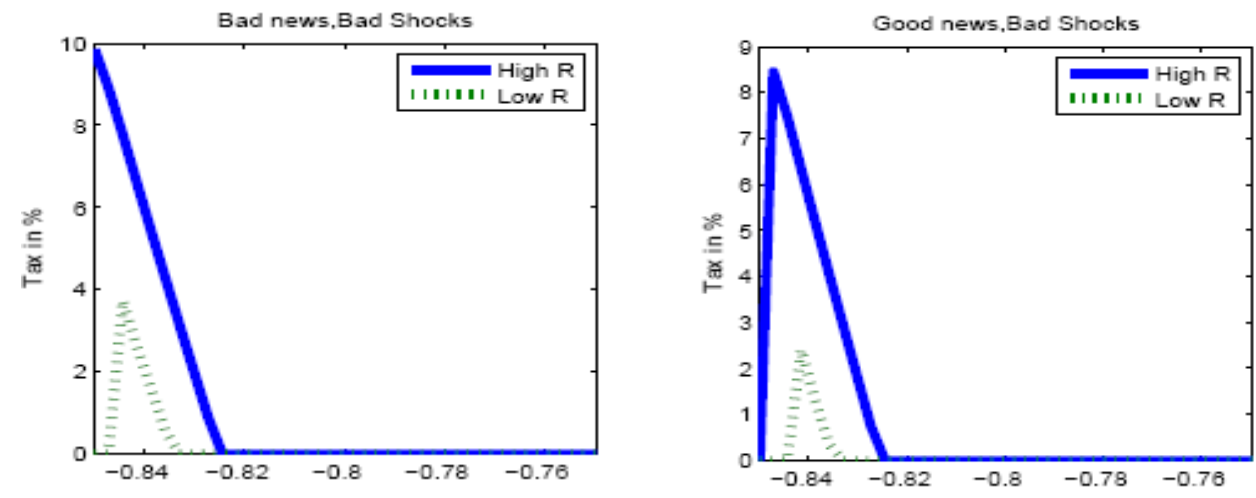
The optimal policies embody large and nonlinear variations. When $b$ is sufficiently high for the collateral constraint to be of little relevance, all three wedges in the planner's optimality conditions are zero and all taxes are zero. When the value of $b$ is sufficiently low for the constraint to bind at $\mathrm{t}+1$ with some probability (for the debt tax) or at $\mathrm{t}$ (for the production tax and subsidy), the policy instruments are activated, and their values increase as $b$ falls (as debt rises). Optimal debt taxes can be as high as 1.4 percent, optimal subsidies on tradables producers can reach a little over 1 percent, and optimal taxes on nontradables producers can be as high as 10 percent.

In light of the complexity of the optimal policy, consider instead simpler policy rules in the form of constant taxes. First, Column (3) of Table 2 shows results for the case in which the taxes are "optimized," in the sense of finding the triple $\left(\tau, s^{T}, \tau^{N}\right)$ that attains the highest social welfare using a simplex routine starting from the average taxes of the optimal policy. Since this is computationally intensive, Column (4) presents results for the case in which the taxes are simply set at the averages of the optimal policy.

The results for these two simple rules show the significant risks embodied in the use of financial policy instruments, and the importance of developing reliable quantitative models to evaluate these policies. The two rules are less effective than the optimal policy by sizable margins, but in particular the effectiveness of the simplest rule set to the averages of the optimal policy is minimal. Relative to the DE without policy in Column (1), the frequency of crisis falls from 2.8 to 2.5 percent, the welfare gain is only 0.4 percent, and the magnitudes of the impact effects on consumption, the real exchange rate and the current account when a crisis hits are only slightly weaker. Moreover, there are many triples of values of the policy instruments that can actually turn welfare losses, so that the economy is better off when exposed to the 2.8 percent risk of financial crises that with suboptimal constant taxes.

\section{Credibility and Optimal Time-Consistent Policy in a Collateral Assets Setup}

In this Section, we provide a quantitative example of the collateral assets setup. Drawing from results obtained Bianchi and Mendoza (2016), we document that again in this environment Fisherian models produce financial crises with realistic features. In addition, the authors demonstrate that optimal financial policy under commitment is time-inconsistent, and therefore its credibility is an issue, but that the optimal, time-consistent policy of a financial regulator that cannot commit to future policies can still be very effective. Complexity, however, is again a hurdle, and there is a large set of "simple financial policy rules" that are much less effective than the optimal policy and can actually be welfare-reducing relative to the decentralized economy without regulation.

\section{(a) The Bianchi-Mendoza Model and the Time-Inconsistency of Financial Policy}

Consider again a small open economy with access to world credit markets, but now assume that private agents use a physical asset in fixed supply (e.g. land or housing) as collateral. To allow the collateral constraint to affect aggregate supply, we assume that agents operate a production technology that again requires intermediate goods priced at a worlddetermined price, but now the constraint matters for production because a fraction of the cost of 
inputs needs to be paid in advance with working capital loans, and these loans are also subject to the collateral constraint. Without loss of generality, we combine the optimization problems of households and firms into the optimization problem of a representative "firm-household."

The representative agent chooses sequences of consumption and bond holdings as in the model of Section 3, but in addition they also choose sequences of asset holdings, $k_{t+1}$, labor supply, $h_{t}$ and intermediate goods, $m_{t}$ so as to solve the following constrained optimization problem:

subject to:

$$
\max E_{0}\left[\beta^{t} \frac{\left(c_{t}-\chi \frac{h^{1+\omega}}{1+\omega}\right)^{1-\sigma}}{1-\sigma}\right], \quad \omega>0, \sigma>1
$$

$$
\begin{array}{cl}
q_{t} k_{t+1}+c_{t}+\frac{b_{t+1}}{R_{t}}=q_{t} k_{t}+b_{t}+\left[z_{t} k_{t}^{\alpha k} m_{t}^{\alpha m} h_{t}^{\alpha h}-p^{m} m_{t}\right], & \alpha k, \alpha m, \alpha h \geq 0, \alpha k+\alpha m+\alpha h \leq 1 \\
\frac{b_{t+1}}{R_{t}}-\theta p^{m} m_{t} \geq-\kappa_{t} q_{t} k_{t,} \quad & 0 \leq \theta \leq 1
\end{array}
$$

The utility function is again CRRA, but now its argument is the Greenwood, Hercowitz and Huffman (1988) utility function, which removes the wealth effect on labor supply by making the marginal rate of substitution between consumption and labor depend only on the latter. The parameter $\omega$ determines the Frisch elasticity of labor supply. The left-hand-side of the budget constraint (25) states that the representative firm-household uses income to purchase assets (at price $q_{t}$ ), consumption goods and bonds. The right-hand-side states that the sources of income are the value of current asset holdings, the payment on current bond holdings, and the profits from production (gross output minus the cost of intermediate goods). The gross production function uses assets, intermediate inputs and labor to generate output. The production function is standard: $F\left(k_{t}, m_{t}, h_{t}\right)=k_{t}^{\alpha k} m_{t}^{\alpha m} h_{t}^{\alpha h}$. Inputs are bought in global markets at a constant price $p^{m}$. Since the same representative agent supplies and demands labor, labor income is included in gross production and the wages bill washes out with the wage income in constraint (25).

The collateral constraint (26) states that total debt, including one-period debt and within-period working capital financing, cannot exceed the fraction $\kappa_{t}$ of the current value of collateral assets. Working capital is needed to pay in advance for a fraction $\theta$ of the total cost of intermediate goods. Notice the timing of working capital is different from the standard Fuerst (1992) working capital setup, in which the net interest rate enters as debt service on working capital and thus becomes part of the price of inputs. This would enhance the financial transmission at work in the model by linking directly the interest rate with the cost of inputs. Instead, here working capital loans are obtained and paid within the production period, so unless the collateral constraint binds working capital is neutral.

This model has three shocks. Standard domestic TFP shocks on gross production, $z_{t}$, and two shocks that capture the effects of global spillovers. First, world real interest rate shocks, $R_{t}$, and second, shocks to the ability to collateralize assets into debt, $\kappa_{t}$. Interest rate shocks are modeled as a standard stationary Markov process that is fitted to U.S. time-series data on short-term real interest rates, and hence can be viewed as a proxy for the mechanism driving 
spillover effects from changes in U.S. monetary policy. Shocks to $\kappa_{t}$ are set following the same approach to model global liquidity shocks as in the liability dollarization examples. Hence, $\kappa_{t}$ follows a two-point $\left(\kappa^{h}>\kappa^{l}\right)$ regime-switching Markov process, with $\kappa^{h}$ corresponding to the regime with high liquidity. Notice that as shown in the Section 4 and elsewhere in the literature (e.g. Mendoza (2010)), shocks to $\kappa$ are not required for Fisherian models to have strong amplification and produce financial crises in quantitative applications. They are used in this collateral assets setup to capture the effects of observed fluctuations in credit availability and LTV ratios driven by global capital markets.

The aggregate supply of capital is $K=1$. If follows then that the competitive equilibrium satisfies the Euler equation (2) and in addition the following conditions:

$$
\begin{gathered}
z_{t} F_{h}\left(1, h_{t}, m_{t}\right)=\chi h_{t}^{\omega} \\
z_{t} F_{m}\left(1, h_{t}, m_{t}\right)=p^{m}\left(1+\theta^{\mu_{t}} / u_{c}(t)\right) \\
q_{t} u_{c}(t)=\beta E_{t}\left[u_{c}(t+1)\left(d_{t+1}+q_{t+1}\right)+\kappa_{t+1} \mu_{+1} q_{t+1}\right], \quad d_{t+1} \equiv z_{t+1} F_{k}\left(1, h_{t+1}, m_{t+1}\right)
\end{gathered}
$$

If the collateral constraint does not bind at $\mathrm{t}$ and $\mathrm{t}+1, \mu_{t}=\mu_{t+1}=0$ and the above conditions would be standard. Condition (27) equates the marginal product of labor with the marginal disutility of labor, which is also the real wage. Condition (28) equates the marginal product of intermediate goods with $p^{m}$. Condition (29) reduces to a standard Euler equation for assets, equating the marginal cost and benefit of buying an extra unit of assets.

If $\mu_{t}>0$, the collateral constraint effectively increases the marginal cost of intermediate goods in condition $(28)$ by the amount $\theta \mu_{t} / u_{c}(t)$, which reduces demand for inputs and hence results in adverse effects on factor allocations and production when the constraint binds. In these states, financial amplification hits aggregate supply because, even if $R_{t}$ and $\kappa_{t}$ are unchanged, a TFP shock of a given size has a more negative effect on demand for inputs and production if the constraint binds than if it does not.

If $\mu_{t+1}>0$, the marginal benefit of accumulating assets rises, because if the constraint is expected to bind the next period, the representative agent takes into account that holding more assets enhances borrowing capacity. Notice this is different from internalizing the price effects of optimal plans, because this relates to the effect of holding more $k_{t+1}$ on the collateral constraint at $\mathrm{t}+1$, not the effects on asset prices either at $\mathrm{t}$ or $\mathrm{t}+1$.

How are asset prices affected by binding collateral constraints? This is harder to explain, because of the forward-looking nature of asset pricing. Following Bianchi and Mendoza (2016), if we apply the standard mathematical treatment of equilibrium asset pricing models to the optimality conditions in order to obtain expressions for the forward solution of asset prices and the equity premium, we can obtain the following results:

$$
q_{t}=E_{t} \sum_{j=0}^{\infty}\left[\prod_{i=0}^{j} E_{t+i}\left(R_{t+1+i}^{q}\right)\right]^{-1} d_{t+1+j,} \quad R_{t+1+i}^{q} \equiv \frac{d_{t+1+i}+q_{t+1+i}}{q_{t+i}}
$$




$$
\begin{aligned}
& E_{t}\left[R_{t+1}^{q}-R_{t}\right]=\frac{1}{E_{t}\left(s d f_{t+1}\right)}\left[\frac{\mu_{t}}{u_{c}(t)}-E_{t}\left(\phi_{t+1} s d f_{t+1}\right)-\operatorname{cov}_{t}\left(R_{t+1}^{q}, s d f_{t+1}\right)\right] \\
& s d f_{t+1}=\frac{\beta u_{c}(t+1)}{u_{c}(t)}, \quad \phi_{t+1} \equiv \kappa_{t+1} \frac{\mu_{t+1}}{u_{c}(t)} \frac{q_{t+1}}{q_{t}}
\end{aligned}
$$

In these expressions, $s d f$ is the stochastic discount factor between dates $\mathrm{t}$ and $\mathrm{t}+1$, and $\phi$ is a term that captures the effect of capital gains on the marginal value of collateral when the constraint binds.

Equation (30) looks like a standard forward solution for asset prices: The asset price equals the expected present discounted value of dividends discounted using the rate of return on equity. The dividend rates and the equity returns, however, are affected by the collateral constraint. The effects on the dividend streams are the result of the higher marginal cost of inputs when the collateral constraint binds, as explained earlier. The effects on the equity returns can be inferred from the equity premium expression (31). If the collateral constraint never binds, the equity premium reduces to the standard expression determined by $\operatorname{cov}_{t}\left(R_{t+1}^{q}, s d f_{t+1}\right)$. But when the collateral constraint binds at date $\mathrm{t}$ and is expected to bind at least in some states of nature at $t+1$, excess returns respond with three effects defined by each of the three terms in the square brackets in the right-hand-side of (31), as identified by Bianchi and Mendoza (2016). The first term represents a "liquidity effect," because assets will command a higher premium when the constraint binds at date $\mathrm{t}$ due to the additional borrowing capacity (i.e. liquidity) they provide that same period. This effect always rises expected excess returns when the constraint binds. The second term represents a "collateral effect," in terms of the benefit that buying more assets at date $\mathrm{t}$ provides by improving borrowing capacity at $\mathrm{t}+1$ if the constraint binds then (notice $\phi_{t+1}$ is positive only if $\mu_{t+1}>0$ ). This effect lowers excess returns. The third effect is a second-order effect operating via the conditional covariance between asset returns and marginal utility. This effect can contribute to increase or reduce excess returns. On one hand, expecting the collateral constraint to bind at $t+1$ makes consumption smoothing harder, making the covariance "more negative." On the other hand, with the constraint already binding at $t$, the covariance may rise as the constraint tightens.

The net effect of the above three effects on excess returns is ambiguous, but in quantitative applications the liquidity premium generally dominates, pushing asset returns sharply higher when the constraint binds. Higher returns in turn imply heavier discounting of dividends, which in turn imply a fall in $q_{t}$. This feeds back into a tighter constraint as the value of collateral is falling, following the Fisherian deflation dynamics. It is also important to note that, unlike in the liability dollarization setup, since asset prices are forward looking, $q_{t}$ is affected by expectations of the constraint becoming binding (i.e. equity returns becoming higher) at any future date along the equilibrium path, not just at date $\mathrm{t}$ or $\mathrm{t}+1$.

The social planner's problem of a constrained efficient regulator in this setup can be written as follows, again using $\varepsilon$ to indicate a vector of the realizations of the three shocks $\varepsilon=(z, R, \kappa)$ for simplicity: 


$$
\begin{gathered}
V(b, \varepsilon)=\max _{c, b^{\prime}, h, m}\left[\frac{\left(c-\chi \frac{h^{1+\omega}}{1+\omega}\right)^{1-\sigma}}{1-\sigma}+\beta E\left[V\left(b^{\prime}, \varepsilon^{\prime}\right)\right]\right] \\
c+\frac{b^{\prime}}{R}=b+\left[z 1^{\alpha k} m^{\alpha m} h^{\alpha h}-p^{m} m\right] \\
q u_{c}\left(c-\chi \frac{h^{1+\omega}}{1+\omega}\right)=\beta E\left[u_{c}\left(\hat{c}^{\prime}-\chi \frac{\hat{h}^{\prime 1+\omega}}{1+\omega}\right)\left(z^{\prime} F_{k}\left(1, \hat{m}^{\prime}, \hat{h}^{\prime}\right)+\hat{q}^{\prime}\right)+\kappa^{\prime} \hat{\mu}^{\prime} \hat{q}^{\prime}\right]
\end{gathered}
$$

The planner is benevolent so it maximizes private utility. It faces the economy's resource constraint (eq. (33)) and the aggregate equivalent of the collateral constraint (eq. (34)). In addition, just as in the liability dollarization setup we had the optimality condition for sectoral allocation of consumption as an implementability constraint, here we have the Euler equation for asset holdings of the representative firm-household as an implementability constraint.

The implementability constraint in the above problem indicates that the planner chooses the socially-optimal allocations taking into account that the collateral values that determine borrowing capacity need to be supported as equilibrium asset prices in private competitive markets. How the planner deals with this requirement is a subtle but fundamentally important aspect of the characterization of planning problems in collateral assets models, and it is the reason why the arguments in the right-hand-side of constraint (35) are written with a "^," as the paragraphs below make clear.

Formulations of the planning problems for collateral assets models like those originally proposed by Bianchi and Mendoza (2010) and Jeanne and Korinek (2010) imposed assumptions that, while maintaining the pecuniary externality highlighted in Section 3 , and thus the incentive to internalize the effect of the debt choice made at date $t$ on asset prices at $t+1$, effectively prevented the social planner from internalizing the effects of that same debt choice on asset prices at date t. ${ }^{8}$ This is a drawback, because of course whether the planner may or may not find it optimal to use its debt choice to alter date-t asset prices should be an endogenous outcome. In fact, Bianchi and Mendoza (2016) show that indeed the planner will have incentives to do so. But more importantly, as will become evident below, forcing the planner to ignore these incentives imposes time-consistency of the optimal policy in an ad-hoc way.

\footnotetext{
${ }^{8}$ In Bianchi and Mendoza (2010), the planner does not face constraint (35) and instead is required to support the same asset pricing function from the decentralized competitive equilibrium without policy. In Jeanne and Korinek (2010), the Euler equation for assets is entered as a constraint but with the pricing function modeled as a "reduced form" that allows the government to internalize the effects of $b$ ' on $q$ ' but not on $q$. In both formulations, by construction, when the planner is at any state $(b, \varepsilon)$ the price $q(b, \varepsilon)$ is independent of the choice of $b$ '.
} 
Once we allow the planner to be subject to the implementability constraint (35), the next key assumption to make is whether the planner is able to commit to future policies or not. If the planner can commit, the variables with "^" can be replaced with their usual forms without "^," which reflects the planner's ability to commit. ${ }^{9}$ Unfortunately, when this is the case, it turns out that the optimal plans of the planner display time inconsistency, and this time-inconsistency relates directly to the incentives to affect asset prices contemporaneously with the debt choice when the constraint binds. Formally, the planner's optimality conditions for consumption and asset prices under commitment are:

$$
\begin{gathered}
\lambda_{t}^{*}=u_{c}(t)-\xi_{t}^{*} u_{c c}(t) q_{t}+\xi_{t-1}^{*} u_{c c}(t)\left[z_{t} F_{k}(t)+q_{t}+\kappa_{t} \mu_{t} q_{t}\right] \\
\xi_{t}^{*}=\xi_{t-1}^{*}\left[1+\kappa_{t} \mu_{t}\right]+\frac{\kappa_{t}\left(\mu_{t} v_{t}^{*}+\mu_{t}^{*}\right)}{u_{c}(t)}
\end{gathered}
$$

Where $\lambda^{*}, \mu^{*}$, and $\xi^{*}$ are the planner's Lagrange multipliers with respect to the budget, borrowing and implementability constraints respectively, $\nu^{*}$ is the multiplier on the planner's complementary slackness condition, and $\mu$ is the multiplier on the borrowing constraint for private agents. From (37), it is clear that the multiplier $\xi^{*}$ follows a positive, non-decreasing process which increases every time that the collateral constraint binds. From (36), the planner values how increasing $c_{t}$ creates a tradeoff by which the collateral constraint weakens at date $\mathrm{t}$ but tightens the previous period. The combination of these two features produces timeinconsistency. The intuition is that if the collateral constraint binds at date t, the planner acting under commitment promises that future consumption will be lower, because via the $s d f$ in the valuation of $q_{t}$, lower expected $c_{t+1}$ props up $q_{t}$ and thus enhances borrowing capacity at t. But at $t+1$, if the planner is given the option to deviate, it will find it suboptimal to stick to that promise. In short, the optimal financial policy that emerges from models in which assets serve as collateral is time-inconsistent, and therefore lacks credibility.

In light of the above, Bianchi and Mendoza (2016) characterize and solve for the optimal policies of a regulator who cannot commit (i.e. optimal, time-consistent financial policies). In this case, the variables with " $\leadsto$ " in constraint (35) are replaced with recursive functions that represent conjectures of the regulator about the optimal plans of future regulators: $\hat{c}^{\prime}=C\left(b^{\prime}, \varepsilon^{\prime}\right), \hat{h}^{\prime}=H\left(b^{\prime}, \varepsilon^{\prime}\right), \hat{q}^{\prime}=Q\left(b^{\prime}, \varepsilon^{\prime}\right), \hat{m}^{\prime}=M\left(b^{\prime}, \varepsilon^{\prime}\right), \hat{\mu}^{\prime}=\mathrm{M}\left(b^{\prime}, \varepsilon^{\prime}\right) . \quad$ The regulator's recursive equilibrium becomes a Markov perfect equilibrium that satisfies the Markov stationarity condition: The recursive functions that characterize the optimal choices of the regulator must match the regulator's conjectured functions for the optimal plans of future regulators.

The setup is more complex than the stylized framework of Section 3 and the liability dollarization model of Section 4, but proceeding in the same logical steps (i.e. deriving the optimality conditions of the time-consistent planner's problems, comparing them with the

\footnotetext{
${ }^{9}$ The problem under commitment also needs as constraints the optimality conditions for the allocations of labor and intermediate goods and the complementary slackness conditions. In principle, the problem without commitment also needs them, but it is possible to demonstrate that these constraints are not binding in this case (see Proposition II in the Appendix to Bianchi and Mendoza (2016)). For the same reason, these constraints were omitted from the formulation of the planner's problem in this paper.
} 
optimality conditions of the decentralized equilibrium without policy, and solving for a schedule of debt taxes that supports the planner's allocations as a decentralized equilibrium with policy) yields the following expression for the optimal debt tax:

$$
\tau_{t}=\frac{E_{t}\left[-\kappa_{t+1} \mu_{t+1}^{*} \frac{u_{c c}(t+1)}{u_{c}(t+1)} Q_{t+1}+\frac{\kappa_{t} \mu_{t}^{*}}{u_{c}(t)} \Omega_{t+1}\right]}{E_{t}\left[u_{c}(t+1)\right]}+\frac{\kappa_{t} \mu_{t}^{*} \frac{u_{c c}(t)}{u_{c}(t)} q_{t}}{\beta R_{t} E_{t}\left[u_{c}(t+1)\right]}
$$

Where $\Omega_{\mathrm{t}+1}$ is short notation for a term that collects all the terms by which the planner's choice of $b_{\mathrm{t}+1}$ affects $q_{\mathrm{t}}$ via the derivatives of the functions that represent the choices of future planners in the right-hand-side of the implementability constraint (35). See Bianchi and Mendoza (2016) for the full expression and the analysis showing that the sign of $\Omega_{\mathrm{t}+1}$ is ambiguous but in quantitative applications it is generally negative.

The optimal financial policy implied by this tax has again both macroprudential and expost intervention components. The macroprudential component of the debt $\operatorname{tax}\left(\tau_{t}^{M P}\right)$ levied at date $\mathrm{t}$ is the one associated with the expectation that the collateral constraint may bind at $t+1$ :

$$
\tau_{t}^{M P}=\frac{E_{t}\left[-\kappa_{t+1} \mu_{t+1}^{*} \frac{u_{c c}(t+1)}{u_{c}(t+1)} Q_{t+1}\right]}{E_{t}\left[u_{c}(t+1)\right]}
$$

Notice this tax is exactly of the form derived in the more general framework of Section 3 (use equation (5) in (6) taking into account that by Markov stationarity $\left.q_{t+1}=Q_{t+1}\right)$. Hence, the planner wants to tax debt contracted at date $t$ when the constraint has positive probability of becoming bindings at $t+1$ in order to bring the private marginal cost of borrowing in line with the social marginal cost, because of the incentive to overborrow produced by the pecuniary externality. Any tax revenue is rebated as a lump-sum transfer, as indicated in Section 3.

The ex-post intervention component of financial policy $\left(\tau_{t}^{F P}\right)$ is given by the other two components of the optimal tax:

$$
\tau_{t}^{F P}=\frac{E_{t}\left[\frac{\kappa_{t} \mu_{t}^{*}}{u_{c}(t)} \Omega_{t+1}\right]}{E_{t}\left[u_{c}(t+1)\right]}+\frac{\kappa_{t} \mu_{t}^{*} \frac{u_{c c}(t)}{u_{c}(t)} q_{t}}{\beta R_{t} E_{t}\left[u_{c}(t+1)\right]}
$$

The sign here is ambiguous because the sign of $\Omega_{\mathrm{t}+1}$ is ambiguous, but since in the quantitative applications $\Omega_{\mathrm{t}+1}<0$ and since the second term of this tax is negative always, again because of the concavity of the utility function, we can "safely" assume that as in Section 4 the ex-post intervention element of the financial policy calls for subsidizing debt when the collateral constraint is already binding. The first term in the above expression indicates that, assuming $\Omega_{\mathrm{t}+1}<0$ when the collateral constraint binds, the planner affects the actions of future planners so as to generate an increase in $q_{t}$ by borrowing more (lowering $b_{t+1}$ ). The second term states that, by borrowing more when the constraint binds, the planner can also prop up the asset price because higher current consumption reduces the denominator of the $s d f$ and thus increases $q_{t}$. 
The numerator of this term is isomorphic in absolute value to the one that determines the macroprudential tax (i.e. it reflects the shadow value of the increase in borrowing capacity that the additional unit of debt generates through its effects on the value of collateral), except that it is evaluated as of date $\mathrm{t}$. With the constraint already binding at date $\mathrm{t}$, borrowing more at $\mathrm{t}$ helps prop up the value of collateral by increasing consumption at $t$, while if the constraint does not bind at $\mathrm{t}$ but can bind at $\mathrm{t}+1$ with some probability, borrowing less at date $\mathrm{t}$ props up the value of collateral at $t+1$ if the constraint binds by increasing consumption at $t+1$.

As in the liability dollarization setup, if the two financial policy instruments result in a net subsidy (i.e. $\tau_{t}<0$ ), the government is assumed to pay for it with lump-sum taxes, which raises the concern noted earlier about the possibility that the subsidy would have to be paid with distortionary taxes. The potential for an overall debt subsidy arises only in states in which the collateral constraint binds and either $\mathrm{E}_{\mathrm{t}}\left[\mu_{t+1}^{*}=0\right]$, in which case $\tau_{t}<0$ for sure since we are still assuming $\Omega_{\mathrm{t}+1}<0$, or $\mathrm{E}_{\mathrm{t}}\left[\mu_{t+1}^{*}>0\right]$ but the revenue from the macroprudential debt tax is not enough to pay for the ex-post intervention subsidies, which would imply $\tau_{t}<0$.

\section{(b) Quantitative Findings}

Bianchi and Mendoza (2016) examine several features of the quantitative predictions of this model, both in terms of the dynamics of macro-aggregates and asset pricing variables, and in terms of comparing solutions without policy, v. solutions with optimal policy with and without commitment, and v. solutions with simple macroprudential policy rules. We focus here only on three key results of their work: First, showing financial amplification in the Fisherian collateral assets model is strong and produces financial crises with realistic features. Second, the optimal, time-consistent policy (i.e. taking into account the planner's inability to commit to future policies) is still effective at reducing the frequency and magnitude of crises. Third, the optimal policy is again a complex time- and state-contingent schedule, and simpler policies, in the form of constant taxes or what Bianchi and Mendoza labeled a "macroprudential Taylor rule," are much less effective and can even be welfare reducing.

The model was calibrated to annual data (1984-2012) for OECD economies. A subset of the parameters is determined directly by drawing from actual data and estimates from the literature, and a second subset is determined by model simulation to match targets from the data. The parameters that are set with the latter are the variability and persistence of TFP, the share of assets in production, the subjective discount factor, and the regime-switching probabilities of $\kappa$. A summary of the calibration is provided in Table 3 (see Bianchi and Mendoza (2016) for full details). The corresponding targets are the variability and persistence of HP-detrended GDP (averages for OECD countries), loan-to-value and net foreign asset-GDP ratios of the U.S., a frequency of crises of 4 percent, and a mean duration of crises of 1 year.

Figure 3 illustrates both the effects of Fisherian financial amplification on macroeconomic dynamics and the effectiveness of the optimal, time-consistent policy at reducing the magnitude of crises. The Figure shows four event windows for financial crises events identified in a long (100,000 periods) time-series simulation of the model. The windows cover nine years, starting 5 years before a financial crisis hits. Financial crises are defined using the methodology proposed by Forbes and Warnock (2012) (the linearly-detrended current accountGDP ratio is two standard deviations above its mean). 
Table 3. Bianchi-Mendoza Calibration for Collateral Assets Model

\begin{tabular}{lll}
\hline Parameters set independently & Value & Source/Target \\
\hline Risk aversion & $\sigma=1$. & Standard value \\
Share of inputs in gross output & $\alpha_{v}=0.45$ & Cross country average OECD \\
Share of labor in gross output & $\alpha_{h}=0.352$ & OECD GDP Labor share $=0.64$ \\
Labor disutility coefficient & $\chi=0.352$ & Normalization to yield average $h=1$ \\
Frisch elasticity & $1 / \omega=2$ & Keane and Rogerson (2012) \\
Working capital coefficient & $\theta=0.16$ & U.S. Working capital/GDP ratio=0.133 \\
Tight credit regime & $\kappa^{L}=0.75$ & U.S. post-crisis LTV ratios \\
Normal credit regime & $\kappa^{H}=0.90$ & U.S. pre-crisis LTV ratios \\
Interest rate & $\bar{R}=1.1 \%, \rho_{R}=0.68$ & U.S. 90-day T-Bills \\
& $\sigma_{R}=1.86 \%$ & \\
\hline Parameters set by simulation & Value & Target \\
\hline TFP shock & $\rho_{z}=0.78, \sigma_{\varepsilon}=0.01$ & OECD average for std. and autoc. of GDP \\
Share of assets in gross output & $\alpha_{k}=0.008$ & Value of collateral matches total credit \\
Discount factor & $\beta=0.95$ & $N F A=-25$ percent \\
Transition prob. $\kappa^{H}$ to $\kappa^{L}$ & $P_{H, L}=0.1$ & 4 crises every 100 years (See Appendix F.2) \\
Transition prob. $\kappa^{L}$ to $\kappa^{L}$ & $P_{L, L}=0$. & 1 year duration of crises (See Appendix F.2) \\
\hline
\end{tabular}

Note: See Bianchi and Mendoza (2016) for details

The continuous, red curves in the event windows of Figure 3 show the strong Fisherian amplification effects that produce large declines in credit, asset prices production and consumption during financial crises. The magnitudes of the declines in asset prices and output are roughly in line with the OECD data, while the declines in consumption in credit are in fact much larger (partly because all intertemporal debt is one-year debt in the model, so the credit constraint forces a large adjustment in consumption).

The blue, dashed curves in Figure 3 represent the dynamics of the optimal, timeconsistent financial policy. The policy reduces sharply the declines in credit, asset prices, and consumption, and it also weakens the fall in output, although by less than in the other cases. This is because financial crises coincide on average with periods of low TFP and a shift to $\kappa^{l}$, and these two exogenous shocks have large adverse effects on production that are independent of policy intervention. In addition, unlike in the case of the ex-post financial policy of the planner in Section 4, the planner without commitment of the collateral assets model does not have wedges to tackle in the factor allocation conditions. When the collateral constraint binds, the marginal cost of inputs rises for both private agents and the planner, but the optimality conditions of the two have the same form. Still, since the planner's $\mu^{*}$ differs from the private agents $\mu$, the planner may want to intervene in factor markets when the constraint binds, but as Bianchi and Mendoza (2016) proved, the optimality conditions for factor allocations of private agents are non-binding constraints for the social planner without commitment. 
Figure 3. Crisis Dynamics with and without Optimal Policy
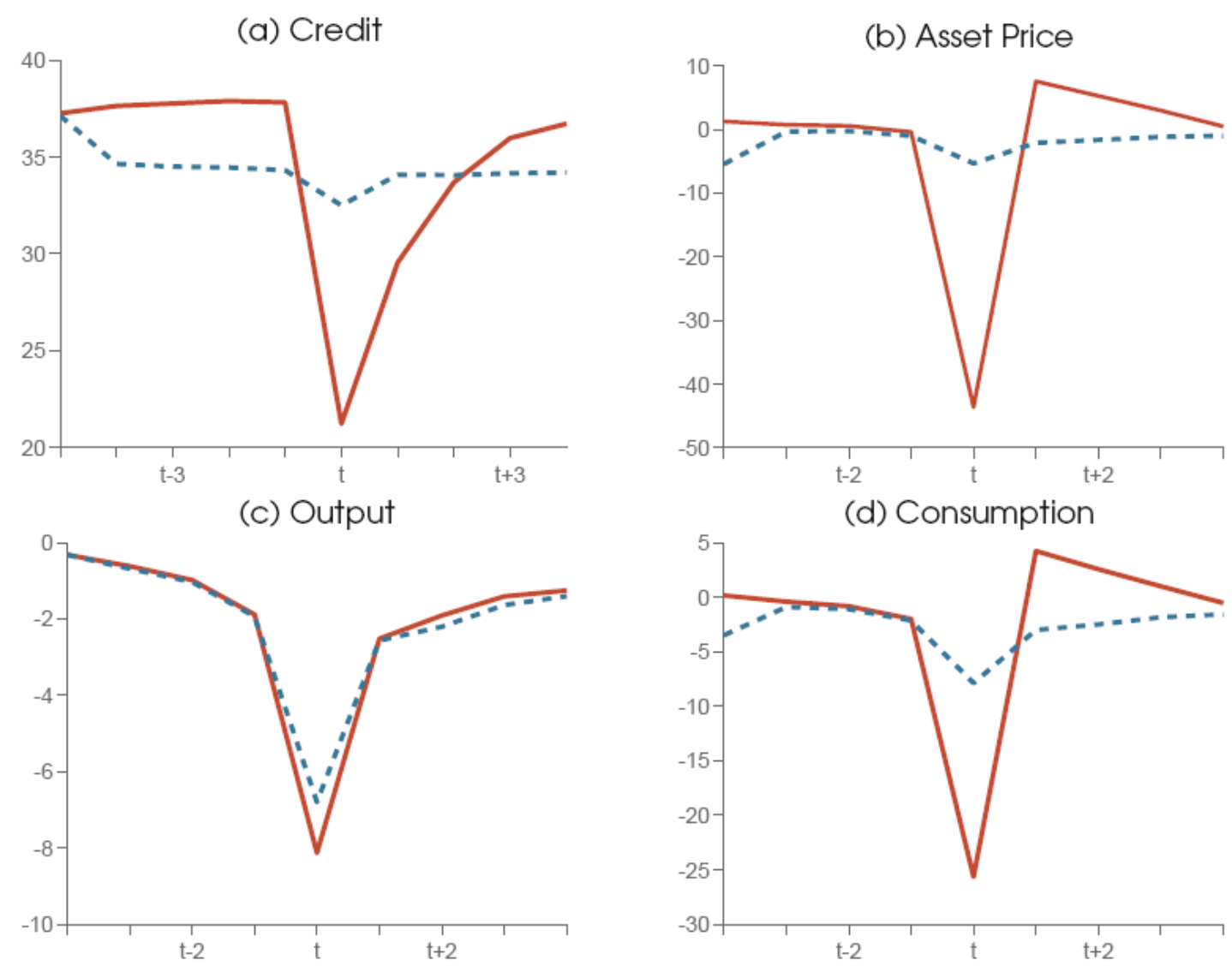

(d) Consumption

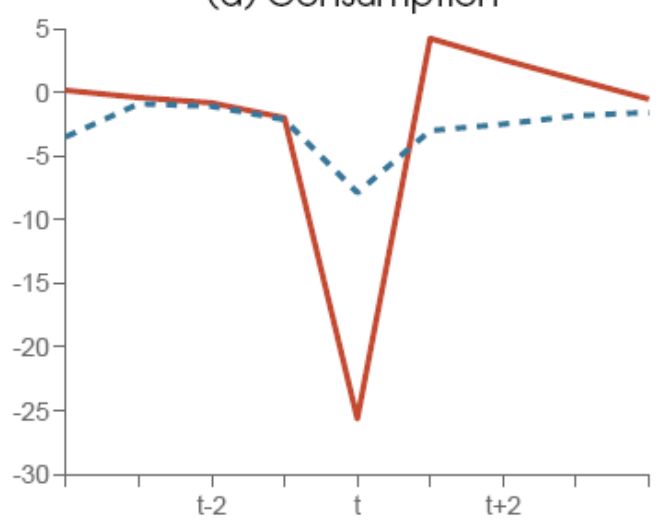

The optimal policy is also very effective at reducing the frequency of crises, and it yields a nontrivial welfare gain. Financial crises have an endogenous probability of 4 percent in the competitive equilibrium without policy v. only 0.02 of a percent with the optimal, timeconsistent policy. The optimal policy yields and average welfare gain of 0.30 percent.

Since the collateral constraint binds infrequently but the expectation that it may bind at $\mathrm{t}+1$ when it does not bind at $\mathrm{t}$ is a frequent event (with 94 percent probability in the stochastic steady state with the optimal policy), the quantitatively relevant element of the policy is the macroprudential debt tax $\left(\tau_{t}^{M P}\right)$. The complexity of this tax under the optimal time-consistent policy is illustrated in Figure 4. Panel (a) shows how the tax varies with the bond position of the economy in "good" states of nature. The tax varies nonlinearly between 0 and 13 percent. Panel (b) shows the time-series dynamics of the tax around crises. The tax rises in the pre-crisis years, from 9 percent five years before the crisis to about 12 percent one year before, then goes to zero, and then rises again to about 5 percent by the fourth year after the crisis.

Given the complexity of the optimal policy, Bianchi and Mendoza (2016) examined the performance of two alternative simpler rules. First, a constant (time- and state-invariant) debt tax. Second, a "macroprudential Taylor rule," according to which the debt tax evolves as a loglinear function of the gap between the debt position and a target value of debt with a given elasticity parameter, and it applies only if the implied tax is positive (if the rule returns a subsidy, the tax is set to zero). Bianchi and Mendoza examined alternative formulations of this 
rule adding other variables from the model. These formulations perform only marginally better and since the rule with just the debt is more parsimonious, they focus on this case. The constant tax and the elasticity of the macroprudential Taylor rule are both "optimized," in the sense that the authors identified parameters for each that yield the largest welfare gain. For the constant tax, they identified the one that yields the largest welfare gain in the 0 to 2 percent interval. For the Taylor rule, they searched over pairs of the elasticity and the target debt.

\section{Figure 4. Optimal, Time-Consistent Macroprudential Debt Tax}

(a) Tax Schedule in Good States

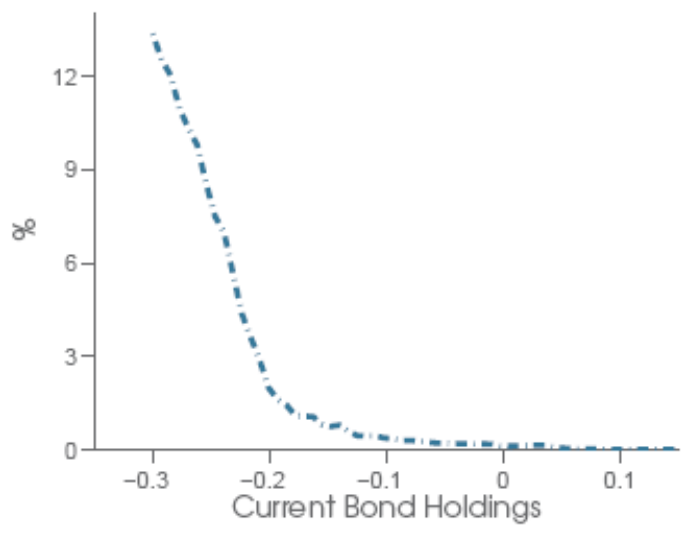

(b) Tax Dynamics around Crises

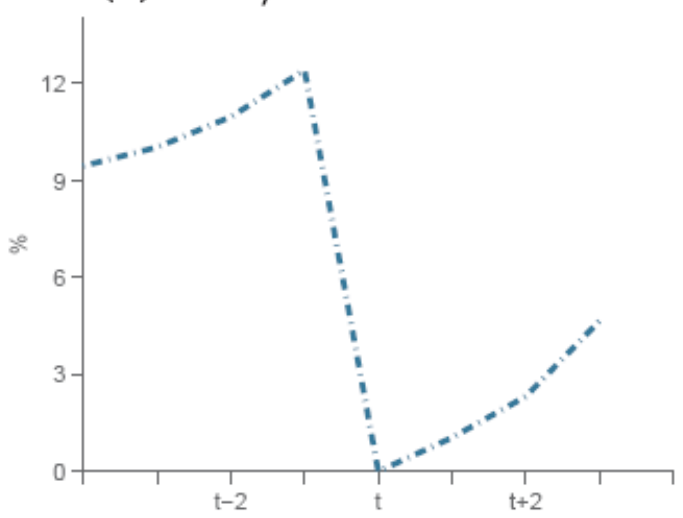

The results show that the constant debt tax, which has an optimized value of 0.6 percent (v. 3.6 percent for the optimal, time-consistent tax), is almost completely ineffective at reducing the magnitude and frequency of crises. Crises occur with 3.6 percent probability (v. 0.02 percent with the optimal policy), and the drops in credit, asset prices, output and consumption during crises are about the same as without policy. The optimized fixed tax yields a negligible welfare gain of only 0.03 percent, $1 / 10^{\text {th }}$ the size of the gain under the optimal policy.

But constant taxes can do much worse. Constant taxes larger than 1.1 percent are actually welfare-reducing, indicating that agents are better off in the economy without regulation, living with a 4 percent probability of a financial crisis than with a permanent debt tax of 1.1 percent. A tax set at the average of the optimal, time-consistent tax would cause a welfare loss of nearly -0.3 percent.

The macroprudential Taylor rule performs better than the constant debt tax, but is still less effective than the optimal policy. It reduces the probability of crisis to 2.2 percent (a little more than half of the crisis probability without policy but much higher than the 0.02 percent under the optimal policy), it mitigates the drops in macro variables and asset prices more, and it yields a welfare gain of nearly 0.1 percent (v. 0.3 percent under the optimal policy and 0.03 percent with the best constant tax). The average debt tax under this rule is 1 percent and it has a correlation with leverage of 0.3 , while the optimal, time-consistent tax has a mean of 3.6 percent and a sharply higher correlation with leverage of 0.7. As with the constant taxes, however, there are several combinations of the debt target and the elasticity of this rule that reduce social welfare relative to the equilibrium without policy.

The reason why both of these simple rules can be so harmful when their parameter structure is not "optimized" is twofold. First, they can call for taxes that remain in place when 
they are not needed (i.e. when credit is tight and the credit constraint is binding or almost binding). Second, they can also call for taxes that remain in place or are too high in "very good times," when the constraint can bind only in the distant future, and thus hampering access to debt is suboptimal. The rationale for these two effects is straightforward, but the magnitude of the quantitative findings is striking. For instance, changing the constant tax from 0.6 to 1.1 percent turns a constant debt tax into a welfare-reducing policy. Hence, these results highlight the relevance of evaluating simple macroprudential rules carefully using models and solution methods that can capture well the global, nonlinear features of financial amplification.

\section{Interactions between Financial and Monetary Policy}

A critical issue in the implementation of financial policy in general, and macroprudential policy in particular, is the interaction with monetary policy. Even if financial authorities can construct relatively simple, time-consistent policy rules that seem effective in models of the class we have examined, their actual effectiveness hinges crucially on how monetary policy responds. The instruments that each policy uses have effects on the variables that each policy targets (e.g. management of credit conditions affects inflation while adjustments of short-term nominal interest rates affect credit conditions), and since the objective functions of monetary and financial authorities generally differ (e.g. monetary authorities focus on inflation, financial authorities focus on credit growth, and both may focus also on the output gap), the potential for inefficiencies resulting from violations of Tinbergen's rule or strategic interaction is evident.

This is an issue regardless of institutional arrangements. In some countries, monetary and financial policies are largely designed and implemented by the central bank, either through a single committee (e.g. the United States) or separate committees (as in the United Kingdom); in others, the monetary and financial authorities are separate entities (e.g. Chile); and in others the central bank is in charge of some but not all of the financial policy decisions (e.g. Mexico). Regardless of the arrangement, considering the interaction of the two policies is important, because even when both are set within the central bank, the areas or committees in charge of the two policies differ.

The dominant approach to design and evaluate monetary policy in many central banks is to use quantitative Neokeynesian DSGE models, typically to conduct inflation targeting with a Taylor rule for a short-term nominal interest rate (the "policy rate"). There are also variants of these models that incorporate financial frictions, often using the Bernanke-Gertler financial accelerator framework following the well-known BGG model proposed by Bernanke et al. (1999). As explained in Section 2, these models are solved with perturbation methods using first- or second-order local approximations, which can be problematic because important features of the financial amplification mechanism and the design of optimal financial policies that hinge on global, nonlinear effects of financial frictions are not accurately captured. On the other hand, Fisherian models are by necessity parsimonious, because the curse of dimensionality hampers our ability to apply global, nonlinear methods to large-scale models like the central banks' DSGE models. Hence, in this Section of the paper, we draw from the work of Carrillo et al. (2016) to discuss the interaction of monetary and financial policies using a variant of the BGG Neokeynesian DSGE model with financial shocks proposed by Christiano et al. (2014). We. acknowledge that the magnitude of the financial amplification created by the Bernanke-Gertler 
accelerator, and thus the effects of both financial frictions and financial policies, would not match the results of a global solution of the same model, but we make this tradeoff so as to shed light on the quantitative implications of the interaction between monetary and financial policies.

\section{(a) Analytical framework}

The model used by Carrillo et al. (2016) is in the vein of the BGG-DSGE setup with "risk shocks" proposed by Christiano et al. (2014). Hence, the model features two sources of inefficiency: First, nominal rigidities in the form of Calvo staggered pricing of differentiated intermediate goods produced under monopolistic competition. Second, costly state verification of entrepreneurs returns by financial intermediaries. Risk shocks enter as shocks to the variance of the entrepreneurs' investment projects. These shocks are viewed as "financial shocks" because they have first-order effects on the interest rate that financial intermediaries charge to entrepreneurs, which in turn affects allocations, prices and welfare via the BGG financial accelerator. Carrillo et al. provide the full details of the model structure, so the discussion here focuses on the aspects of the model that drive the interaction between monetary and financial policies, and the quantitative implications for the role of Tinbergen's rule and strategic interaction between the two policies.

For simplicity, Carrillo et al. (2016) focus on monetary and financial policies that follow isoelastic rules. The monetary policy literature has studied conditions under which rules of this form can be consistent with optimal Ramsey policy problems or with the optimal policy for policymakers with quadratic loss functions. These conditions are generally violated in monetary policy applications of DSGE models, but still we focus on isoelastic rules because of their prevalent use in policymaking. On the monetary policy side, consider a simple Taylor rule driving the evolution of the policy interest rate:

$$
\left(1+i_{t}\right)=(1+i)\left(\frac{1+\pi_{t}}{1+\bar{\pi}}\right)^{a_{\pi}}
$$

Where $i$ is the long-run nominal interest rate, $\bar{\pi}$ is the inflation target and $a_{\pi}$ is the elasticity of the Taylor rule with respect to deviations of inflation from its target.

On the financial policy side, the optimality conditions of the optimal contract for the supply of capital to entrepreneurs in the BGG model (corresponding to the problem of maximizing the entrepreneurs expected returns subject to participation constraints of intermediaries for each realization of the risk shock), yield the familiar external financing premium or credit spread. Introducing financial policy into the model, the external financing premium takes this form:

$$
E_{t}\left[\frac{r_{t+1}^{k}}{R_{t}}\right]=s\left(\frac{q_{t} k_{t}}{n_{t}}, \sigma_{\omega, t}\right)\left(1-\tau_{f, t}\right)
$$

In this expression, $r_{t+1}^{k}$ is the real rate of return on capital, $R_{t}$ is the opportunity cost of investing (the gross real interest rate), $q_{t}$ is the price of capital, $k_{t}$ is the aggregate capital of 
entrepreneurs, $n_{t}$ is their aggregate net worth (the sum of their aggregate equity plus any labor income they are paid), $\sigma_{\omega, t}$ is the date-t variance of idiosyncratic shocks to the return of entrepreneurs' investment projects (the risk shock), $\tau_{f, t}$ is a tax (if positive) or subsidy (if negative) on the return to investing in government bonds $\left(R_{t}\right)$ instead of investing in physical capital, and $s($.$) represents the pre-tax external financing premium at which entrepreneurs$ borrow from financial intermediaries under the optimal Bernanke-Gertler contract. The function $s($.$) is increasing and convex in the leverage ratio \left(q_{t} k_{t} / n_{t}\right)$, and increasing in $\sigma_{\omega, t}$

The financial policy rule is given by the following iso-elastic function:

$$
\tau_{f, t}=\tau_{f}\left[E_{t}\left(\frac{r_{t+1}^{k}}{R_{t}}\right) /\left(\frac{r^{k}}{R}\right)\right]^{a_{r}}
$$

where $R$ is the long-run real interest rate that satisfies $R=(1+i) /(1+\bar{\pi}), r^{k}$ is the long-run gross real of return on capital and $\tau_{\mathrm{f}}$ is a long-run value of the financial tax consistent with attaining the long run value of $r^{k}$. The intuition is that with $a_{r}>0$, increases in the credit spread above its long-run value (in response, for example, to a positive risk shock) induce an increase in the financial tax, which lowers the opportunity cost of funds and thus rises credit and investment demand to offset the adverse effects of the risk shock.

The interaction between monetary and financial policies can be characterized intuitively with graphs as follows. The essential role of the Neokeynesian side of the model is to produce an upward-sloping Phillips curve, which together with aggregate demand generates the equilibrium inflation rate and output gap. This is illustrated in panel (a) of Figure 5. PC is the Phillips curve and $y^{d}$ is the aggregate demand curve. On the financial side of the model, the BernankeGertler financial accelerator distorts the credit market and the demand for capital goods from entrepreneurs. Their demand for capital follows from a similar Euler equation for assets as the one studied in Section 4, which taking as given asset prices yields a downward sloping demand curve, because of the decreasing marginal product of capital. The financial intermediaries' supply of funds to entrepreneurs in this market is determined by the BGG external financing premium. These two curves generate the equilibrium capital allocation and rate of return on capital, as illustrated in panel (b) of Figure 5. The curve labeled efp (external financial premium) represents the supply of capital provided by the funding from financial intermediaries. The curve $k^{d}$ is the entrepreneurs demand for capital.

Figure 5. Monetary and Financial Policy Interactions

(b) Aggregate supply \& demand

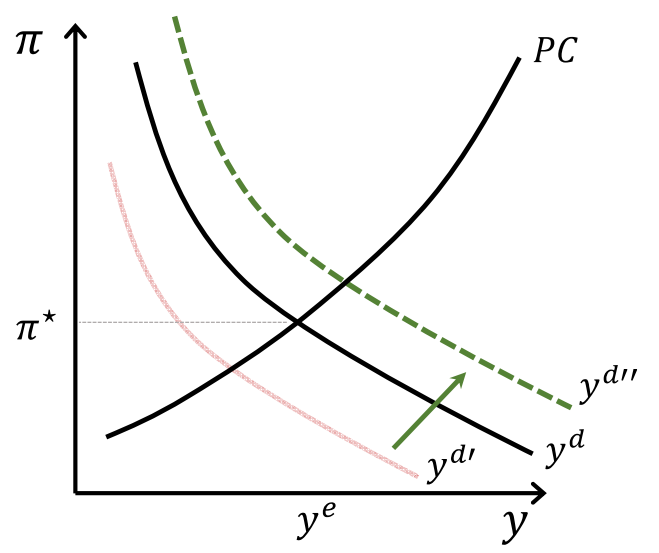

(a) Entrepreneurs capital supply \& demand

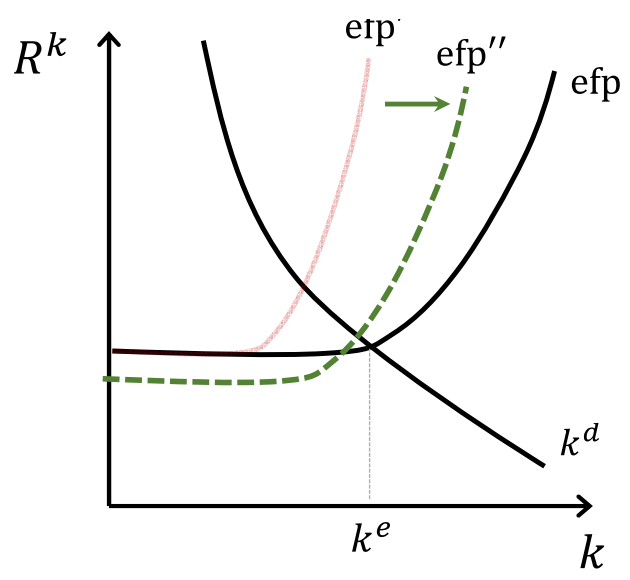


Assume a risk shock hits the economy. The financial intermediaries' supply curve shifts inward to efp', because of the effect of the higher variance of idiosyncratic shocks to entrepreneurs' returns on the optimal credit contract. This reduces the equilibrium allocation of capital and increases its rate of return. In turn, the lower demand for capital shifts aggregate demand inward to $y^{d}$, reducing inflation and output. Thus, the financial shock has effects on all macroeconomic aggregates, including those that monetary and financial policies target.

If monetary policy is implemented without financial policy, the aim would be to reduce $i$ so as to offset the declines in inflation and output. Ideally the policy would seek to return output and inflation to their targets, but for some arbitrarily-specified Taylor rule the idea would be to shift aggregate demand outward, say to $y^{d}$ ". Because of the Bernanke-Gertler costly-state-verification friction, however, the lower $i$ and higher expected inflation reduce the real interest rate, and this shifts the supply of capital outward to efp" and thus alters equilibrium in the capital market and the credit spread, which the financial authority cares for. On the other hand, if financial policy is implemented without monetary policy, financial policy would be relaxed (i.e. $\tau_{f, t}$ rises) so as to shift the supply of funds outward. Ideally, the policy would seek to restore the target spread and capital levels, but for an arbitrary elasticity of the financial tax rule the shift is to efp" (to keep the plots simple, we assume it is the same shift as in the monetary policy example). As investment demand rises, however, aggregate demand shifts outward (again for simplicity it is also a shift to $y^{d}$ ") and the equilibrium inflation and output, which the monetary authority cares for, change. In short, since $E_{t}\left(r_{t+1}^{k} / R_{t}\right) /\left(r^{k} / R\right)$ and $\left(1+\pi_{t}\right) /(1+\bar{\pi})$ are general equilibrium outcomes that depend on $\left(i_{t}, \tau_{f, t}\right)$, the actions of one policy authority affect the target variable and payoff of the other.

The above arguments raise two key issues. First, assuming that the goal is to maximize social welfare, Tinbergen's rule applies: using two separate instruments $\left(i_{t}\right.$ and $\left.\tau_{f, t}\right)$ to target two variables (inflation and the credit spread) should be at least as good as using a single instrument to target both variables. Intuitively, there are two inefficiencies in the economy, sticky prices and costly state-verification, and using one policy instrument to tackle each should be (weakly) better than a single instrument trying to tackle both. Second, if monetary and financial authorities have different payoff functions, a suboptimal policy mix will result, because of inefficient strategic interaction. Hence, a cooperative equilibrium with coordination of financial and monetary authorities dominates a non-cooperative regime. Analytically, the two issues are straightforward applications of standard findings from the literature on Tinbergen's rule and strategic interaction in economic policy. The main concern is whether these are quantitatively relevant issues.

\section{(b) Quantitative Findings}

We omit the full details of the model structure, functional forms and parameter calibration of the model, which are provided in the Carrillo et al. (2016) study. The calibration was done for the United States at a quarterly frequency and several parameter values were taken from the model estimation in the work of Christiano et al. (2014), with the parameters of the financial accelerator structure taken from Bernanke et al. (1999). It is also important to note that the model is solved with a second-order approximation in order to obtain more accurate 
welfare assessments. The emphasis in the discussion below is on the main results related to Tinbergen's rule and strategic interaction of financial v. monetary policies.

In order to evaluate these two issues quantitatively, we need to define the welfare effects of alternative policy regimes. As in the previous exercises measuring the welfare effects of debt taxes, we follow again the standard Lucas approach to measure welfare as a compensating (time- and state-invariant) change in consumption that equates welfare under a policy regime $\mathrm{v}$. a baseline benchmark. In this case, we define the benchmark as the deterministic stationary state of the economy, because by construction this steady state is independent of the elasticities of the monetary and financial policy rules. Moreover, by parameterizing the intercept coefficients of the policy rules, the deterministic steady state is constructed so that the real effects of the nominal rigidities and the financial friction wash out, which makes the deterministic steady state Pareto efficient. Thus, the welfare effect of a particular policy regime is the percentage increase in consumption needed to make individuals indifferent between expected lifetime utility under that policy regime and lifetime utility in the deterministic steady state. Larger increases indicate larger welfare losses.

To examine the quantitative relevance of Tinbergen's rule, the goal is to compare an environment with separate monetary and financial policy rules as described earlier with one in which there is only a monetary policy rule but augmented to include financial stability considerations. In particular, this monetary rule takes this form:

$$
\left(1+i_{t}\right)=(1+i)\left(\frac{1+\pi_{t}}{1+\bar{\pi}}\right)^{\hat{a}_{\pi}}\left[E_{t}\left(\frac{r_{t+1}^{k}}{R_{t}}\right) /\left(\frac{r^{k}}{R}\right)\right]^{-\hat{a}_{r}}
$$

Notice that in this rule the coefficient on the credit spread, $\hat{a}_{r}$, enters with a negative sign, indicating that when the spread rises, the interest rate falls to help offset the adverse effect on aggregate demand due to the fall in investment.

Carrillo et al. (2016) computed the elasticity pairs under the two-rule regime $\left(a_{\pi}, a_{r}\right)$, with policy rules (41) and (43), and under the one-rule regime $\left(\hat{a}_{\pi}, \hat{a}_{r}\right)$, with policy rule (44), that minimize the social welfare loss relative to the deterministic steady state. The resulting elasticities are $\left(a_{\pi}=1.2, a_{r}=1.6\right)$ v. $\left(\hat{a}_{\pi}=1.25, \hat{a}_{r}=0.26\right)$, and social welfare is 34 percent higher under the two-rule regime that under the one-rule regime. Notice that both monetary and financial policies are "too tight" under the latter, with a response to inflation that increases the interest rate by more than under the two-rules regime and a response to the spread that does not relax financial conditions enough. ${ }^{10}$ Financial policy in particular is significantly tighter. These differences result in significant differences in impulse response functions in response to a risk shock (see Figure 3 in Carrillo et al. (2016)). In particular, comparing the one-rule regime v. the two-rule regime, output (investment) at its through falls 30 (115) basis points below the deterministic steady state v. less than 20 (50) basis points, equity prices fall 200 basis points v. less than 100 basis points, and the time series dynamics of consumption are significantly smoother with the two rules. In short, aiming to expand the Taylor rule to target the credit

${ }^{10}$ The elasticity coefficients on the credit spread in (43) and (44) are comparable because condition (42) can be rewritten as $\mathrm{E}_{\mathrm{t}}\left[r_{t+1}^{k}\right] \mathrm{E}_{\mathrm{t}}\left[1+\pi_{t+1}\right]=s(t)\left(1-\tau_{f, t}\right)\left(1+i_{t}\right)$, so the financial tax and the interest rate have isomorphic effects on the supply-of-capital condition. The connections between policy instruments and targets of monetary and financial policies are also evident in this expression. 
spread together with inflation targeting results in a quantitatively significant violation of Tinbergen's rule.

Consider next the quantitative implications of strategic interaction. To this end, we need to spell out the payoff functions of policy authorities. If financial and monetary authorities have the same payoff function (whether social welfare or minimizing a common loss function), there is obviously no conflict, in the sense that a Nash game in which each policy authority chooses the elasticity of its rule taking as given the elasticity of the rule of the other authority yields the same outcome as a Cooperative equilibrium. ${ }^{11}$ When the payoff functions differ, however, the results are very different as documented below.

Define the payoff functions following Williams (2010), so that each policy authority aims to minimize a loss function defined by the sum of the variances of their target and instrument variables (i.e. for the central bank, the sum of the variances of inflation and the policy interest rate, for the financial authority, the sum of the variances of the credit spread and the financial tax). Carrillo et al (2016) compute reaction functions in the $\left(a_{\pi}, a_{r}\right)$ space, with the central bank choosing the Taylor elasticity coefficient that minimizes its loss function for a given value of the financial tax elasticity, $a_{\pi}^{*}\left(a_{r}\right)$, and the financial authority choosing the financial tax elasticity that minimizes its loss function for a given value of the Taylor elasticity, $a_{r}^{*}\left(a_{\pi}\right)$. The Nash equilibrium is the intersection of these reaction curves, and the Cooperative equilibrium is the pair $\left(a_{\pi}, a_{r}\right)$ that minimizes the equally-weighted sum of the two loss functions. Figure 6 shows the reaction curve of the monetary authority (red, dashed curve), the financial authority (blue, continuous curve) together with the Nash and Cooperative equilibria, and in addition it shows the bliss points of each authority and the "first best" point at which social welfare is maximized (instead of the joint loss function minimized as in the Cooperative equilibrium).

\section{Figure 6. Reaction Curves, Cooperative \& Nash Equilibria}

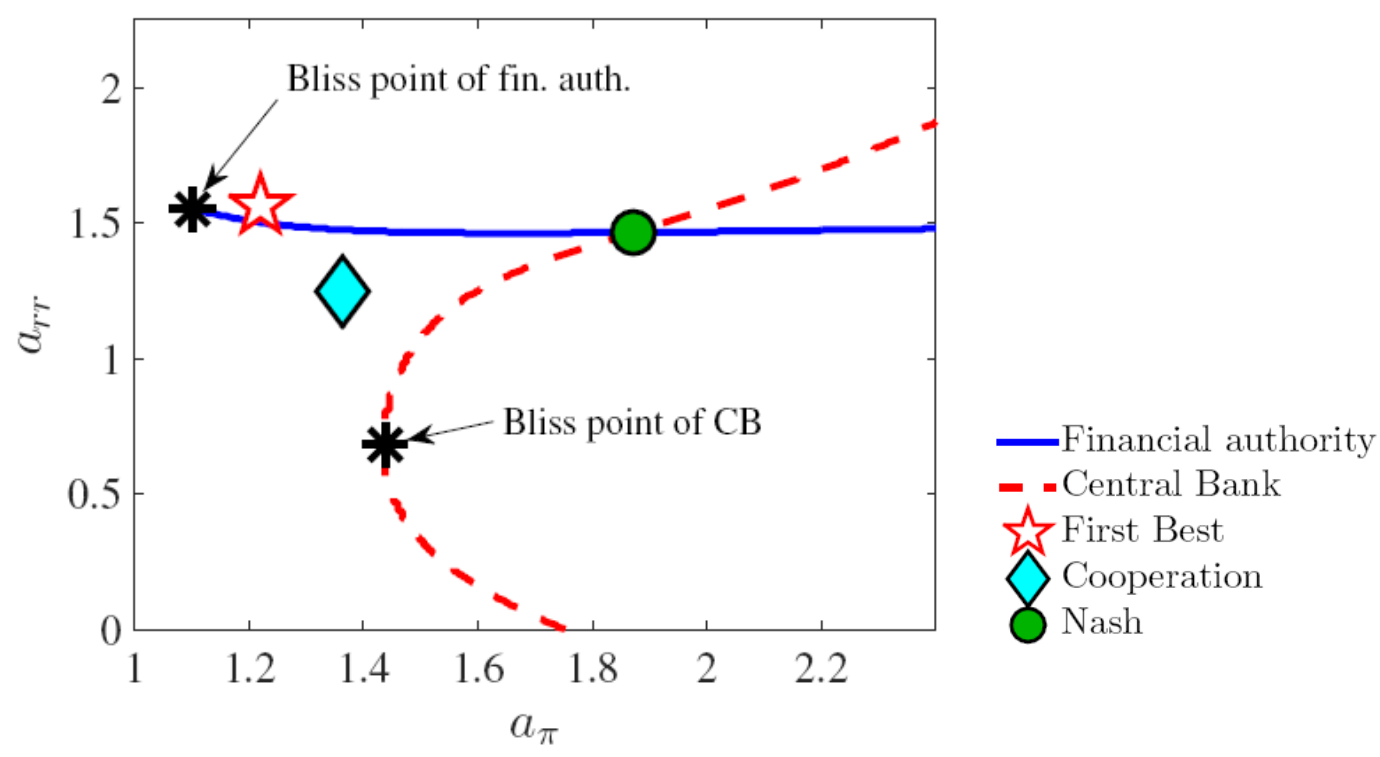

\footnotetext{
${ }^{11}$ The games Carrillo et al. (2016) solve are one-shot games in which payoffs are defined by the welfare costs of choices of the policy rule elasticities (i.e. the payoffs take into account the short- and long-run effects of changing the elasticities on equilibrium prices and allocations).
} 
The Nash equilibrium yields a welfare loss of -7.26 percent relative to the first best, while the welfare loss in the Cooperative equilibrium is -1.31 percent. Hence, failure to coordinate policies has a large social cost. The social benefit of cooperation by monetary and financial authorities is roughly 6 percentage points. Moreover, as the Figure indicates, the Nash equilibrium yields policies that are "too tight" relative to the Cooperative equilibrium. In the former, the elasticities of the monetary and financial rules are $\left(a_{\pi}=1.9, a_{r}=1.4\right)$, while in the latter they $\operatorname{are}\left(a_{\pi}=1.35, a_{r}=1.25\right)$.

It is also important to note that the nonlinear shape of the reaction curves is indicative of shifting preference by the policy authorities for adjusting the elasticities of their policy rules as strategic complements v. strategic substitutes. In particular, the reaction curve of the monetary rule changes from adjusting $a_{\pi}$ as a strategic substitute for $a_{r}$ if $a_{r}<0.7$ to adjusting it as a strategic complement if $a_{r}$ rises above 0.7 . The reaction curve of the financial authority is slightly convex but always consistent with strategic substitutes.

\section{Conclusions}

Macroprudential policy holds the promise of becoming a powerful, effective tool to reduce the magnitude and frequency of financial crises, and thereby increase social welfare. This is a theoretical and quantitative prediction that follows from several studies based on Fisherian models of financial crises (i.e. models in which borrowing capacity is linked to marketdetermined collateral values via occasionally binding credit constraints). Financial amplification, defined as larger responses of macroeconomic aggregates to shocks of standard magnitudes when the collateral constraint binds, is significant, and results in model-generated financial crises broadly consistent with actual financial crises. Market failure, in the form of pecuniary externalities because private agents do not internalize the effect of their borrowing choices on collateral values, justifies policy intervention in order to bring private marginal costs of borrowing in line with social marginal costs. Quantitatively, optimal financial policies designed to maximize social welfare taking these externalities into account reduce sharply the probability and severity of financial crises. Hence, in calibrated Fisherian models, optimal macroprudential policies have proven to be very effective.

In practice, however, effective implementation of Fisherian policies has to cope with three important limitations discussed in this paper:

1) The optimal policy in Fisherian models is a complex time- and state-contingent policy that follows a non-linear pattern of adjustment depending on the phase of the credit cycle and on the size of domestic and external shocks hitting the economy. In particular, optimal financial policies vary widely across values of external shocks in the form of fluctuations in world interest rates, global liquidity conditions, and news about global fundamentals.

2) If collateral values hinge on expectations of future outcomes, the optimal policy under commitment is time-inconsistent, and hence the credibility of financial authorities is called into question. Fisherian models can be upgraded to design and evaluate optimal, time-consistent policies. The resulting policies are again very effective but 
also very complex. Simple policy rules optimized to generate the largest welfare gain are much less effective than the optimal policies, and setting the parameters of simple rules without optimizing them in this way can result in significant welfare losses that make agents worse off than in an economy left to suffer deep financial crises with low probability and no policy intervention.

3) The interaction of monetary and financial policies in the determination of equilibrium allocations and prices that the authorities in charge of each policy care about raises well-known issues related to Tinbergen's Rule and strategic interaction. These issues are quantitatively, significant. Using monetary policy with a Taylor rule augmented with financial stability considerations is significantly inferior to using separate monetary and financial policy rules. Strategic interaction in the setting of elasticities of separate financial and monetary rules results in equilibria that are significantly inferior to cooperative equilibria. Both the use of an augmented monetary rule and the non-cooperative setting of separate financial and monetary rules produce environments in which policies are too tight relative to optimal or cooperative regimes.

There are other important obstacles that the design of effective macroprudential policy still has to face and that this paper did not examine. Heterogeneity in borrowers and lenders is a critical issue. The research discussed in this paper is all based on representative-agent settings. In practice, the financial conditions and the vulnerability to shocks varies widely across lenders and borrowers of various types. The optimal policy, therefore, is very likely to display additional complexity as it will need to vary across the cross-section of agents. For the same reason, simple rules present additional challenges, because even if rules are made time-varying they can still be inefficient and welfare-reducing because of large adverse effects for subsets of agents. Other important issues include interactions with other financial frictions in addition to Fisherian collateral constraints (e.g. moral hazard or informational frictions) and international implications such as the optimal design of financial policies that apply to domestic v. external credit relationships (e.g. capital controls) and the international coordination of financial policies. 


\section{References}

Aiyagari, S.R., and Gertler, M. (1999). "'Overreaction' of Asset Prices in General Equilibrium”. Review of Economic Dynamics, vol. 2, no. 1, 3-35.

Benigno, G., Chen, H., Otrok, C., Rebucci, A., and Young, E. R. (2013). "Financial Crises and Macro-prudential Policies". Journal of International Economics, vol. 89, no. 2, 453-470.

Bernanke, B. (2010). "Causes of the Recent Financial and Economic Crisis, Before the Financial Crisis Inquiry Commission". September 2, 2010. Washington, DC: Board of Governors of the Federal Reserve System.

Bernanke, B., and Gertler, M. (1989). "Agency Costs, Net Worth, and Business Fluctuations". The American Economic Review, vol. 79, no. 1, 14-31.

Bernanke, B., Gertler, M., and Gilchrist, S. (1999). "The Financial Accelerator in a Quantitative Business Cycle Framework". Handbook of Macroeconomics, vol. 1, ed. John B. Taylor and Michael Woodford, 1341-1393.

Bianchi, J. (2011). "Overborrowing and Systemic Externalities in the Business Cycle". The American Economic Review, vol. 101, no. 7, 3400-3426.

Bianchi, J., Liu, C., and Mendoza, E. G. (2016). "Fundamentals News, Global Liquidity and Macroprudential Policy". Journal of International Economics, vol. 99, no. 1, 2-15.

Bianchi, J., and Mendoza, E.G. (2010). "Overborrowing, Financial Crises and 'Macroprudential' Policy". NBER Working Paper No. 16091, http://www.sas.upenn.edu/ egme/wp/w16091.pdf .

Bianchi, J., and Mendoza, E.G. (2016). "Optimal Time-Consistent Macroprudential Policy," forthcoming, Journal of Political Economy, http://www.sas.upenn.edu/ egme/wp/w19704.pdf .

Borio, C. (2003). "Towards a Macroprudential Framework for Financial Supervision and Regulation?". CESifo Economic Studies, vol. 49, no. 2, 181-216.

Carrillo, J., Mendoza, E.G., Nuguer, V., and Roldán-Peña, J. (2016). "Tight Money-Tight Credit: Tinbergen's Rule and Strategic Interaction in the Conduct of Monetary and Financial Policies". Unpublished Manuscript, Bank of Mexico.

Christiano, L.J., Motto, R., and Rostagno, M. (2014). "Risk Shocks". The American Economic Review, vol. 104, no. 1, 27-65.

De Groot, O., Durdu, B., and Mendoza, E.G. (2016). "Global v. Local Methods in the Quantitative Analysis of Open-Economy Models with Incomplete Markets." Unpublished Manuscript, University of Pennsylvania. 
Durdu, C.B., Mendoza, E.G., and Terrones, M.E. (2009). "Precautionary Demand for Foreign Assets in Sudden Stop Economies: An Assessment of the New Merchantilism". Journal of Development Economics, vol. 89, no. 2, 194-209.

Durdu, C.B., Nunes, R., and Sapriza, H. (2013). "News and Sovereign Default Risk in Small Open Economies.'. Journal of International Economics, vol. 91, no. 1, 1-17.

Eaton, J., and Gersovitz, M. (1981). "Debt with Potential Repudiation: Theoretical and Empirical Analysis." Review of Economic Studies, vol. 48, no. 2, 289-309.

Fisher, I. (1933). "The Debt-Deflation Theory of Great Depressions." Econometrica, vol. 1, no. $4,337-357$.

Forbes, K.J., and Warnock, F.E. (2012). "Capital Flow Waves: Surges, Stops, Flight and Retrenchment." Journal of International Economics, vol. 88, no.2, 235-251.

Fuerst, T.S. (1992). "Liquidity, Loanable Funds, and Real Activity." Journal of Monetary Economics, vol. 29, no. 1, 3-24

Gertler, M., Gilchrist, S., and Natalucci, F.M. (2007). "External Constraints on Monetary Policy and the Financial Accelerator." Journal of Money, Credit, and Banking, vol. 39, no. 2-3, $295-330$.

Greenwood, J., Hercowitz, Z., and Huffman, G. (1988). "Investment, Capital Utilization and the Real Business Cycle." The American Economic Review, vol. 78, no. 3, 402-417.

Hernandez, J., and Mendoza, E.G. (2016). "Optimal v. Simple Financial Policy Rules in a Production Economy with 'Liability Dolarization." forthcoming, Ensayos Sobre Politica Economica.

Jeanne, O. and Korinek, A. (2010). "Managing Credit Booms and Busts: A Pigouvian Taxation Approach." NBER Working Paper No. 16377.

Keane, M. and Rogerson, R. (2012). "Micro and Macro Labor Supply Elasticities: A Reassessment of Conventional Wisdom." Journal of Economic Literature, v. 50, no. 2, 464-476.

Kiyotaki, N., and Moore, J. (1997). "Credit Cycles". Journal of Political Economy, vol. 105, no. $2,211-248$.

Korinek, A. (2011). "Excessive Dollar Borrowing in Emerging Markets: Balance Sheet Effects and Macroeconomic Externalities." Unpublished manuscript, University of Maryland.

Mendoza, E.G. (2002). "Credit, Prices, and Crashes: Business Cycles with a Sudden Stop," in Preventing Currency Crises in Emerging Markets, ed. by S. Edwards and J. Frankel, NBER, U. of Chicago Press. 
Mendoza, E.G. (2005). "Real Exchange Rate Volatility and the Price of Nontradable Goods in Economies Prone to Sudden Stops." Economia, Fall 2005.

Mendoza, E.G. (2010). "Sudden Stops, Financial Crisis, and Leverage". The American Economic Review, vol. 100, no. 5, 1941-1966.

Mendoza, E.G., and Quadrini, V. (2010). "Financial Globalization, Financial Crises and Contagion". Journal of Monetary Economics, vol. 57, 24-39.

Mendoza, E.G., and Smith, K.A. (2006). "Quantitative Implications of a Debt-deflation Theory of Sudden Stops and Asset Prices." Journal of International Economics, vol. 70, no. 1, 82-114.

Mendoza, E.G., and Smith, K.A. (2014). "Financial Globalization, Financial Crises, and the External Portfolio Structure of Emerging Markets". Scandinavian Journal of Economics, vol. 116, no. 1, 20-57.

Mendoza, E.G., and Terrones, M.E. (2012). "An Anatomy of Credit Booms and Their Demise". NBER Working Paper No. 18379.

Merton, R.M. (2009). "Observations on the Science of Finance in the Practice of Finance". Muh Award Lecture, Massachusetts Institute of Technology, March $5^{\text {th }}$, 2009, Cambridge, MA.

Ottonello, P. (2015). "Optimal Exchange-Rate Policy under Collateral Constraints and Wage Rigidity". Unpublished Manuscript, University of Michigan.

Schmitt-Grohe, S. and Uribe, M. (2016). "Multiple Equilibria in Open Economy Models with Collateral Constraints: Overborrowing Revisited." forthcoming, Ensayos Sobre Politica Economica.

Shin, H.S. (2013). "The Second Phase of Global Liquidity and Its Impact on Emerging Economies". Mimeo, Princeton University.

Williams, J.C. (2010). "Monetary Policy in a Low Inflation Economy with Learning". FRBSF Economic Review, 1-12. 